\title{
Eddy covariance emission and deposition flux measurements using proton transfer reaction - time of flight - mass spectrometry (PTR-TOF-MS): comparison with PTR-MS measured vertical gradients and fluxes
}

\author{
J.-H. Park ${ }^{1,2, *}$, A. H. Goldstein ${ }^{1,3}$, J. Timkovsky ${ }^{2}$, S. Fares ${ }^{1,4}$, R. Weber ${ }^{1}$, J. Karlik ${ }^{5}$, and R. Holzinger ${ }^{2}$ \\ ${ }^{1}$ Department of Environmental Science, Policy, and Management, University of California, Berkeley, CA 94720, USA \\ ${ }^{2}$ Institute for Marine and Atmospheric Research Utrecht, Princetonplein 5, 3584 CC, Utrecht, The Netherlands \\ ${ }^{3}$ Department of Civil and Environmental Engineering, University of California, Berkeley, CA 94720, USA \\ ${ }^{4}$ Consiglio per la Ricerca e la sperimentazione in Agricoltura - Centro di ricerca per lo studio delle Relazioni tra Pianta e \\ Suolo, Rome, Italy \\ ${ }^{5}$ University of California Cooperative Extension, Bakersfield, CA 93307, USA \\ *now at: Institute of Alpine and Arctic Research (INSTAAR), University of Colorado, Boulder, CO 80309-0450, USA
}

Correspondence to: A. H. Goldstein (ahg@ berkeley.edu)

Received: 25 July 2012 - Published in Atmos. Chem. Phys. Discuss.: 15 August 2012

Revised: 30 January 2013 - Accepted: 31 January 2013 - Published: 6 February 2013

\begin{abstract}
During summer 2010, a proton transfer reaction - time of flight - mass spectrometer (PTR-TOF-MS) and a quadrupole proton transfer reaction mass spectrometer (PTR-MS) were deployed simultaneously for one month in an orange orchard in the Central Valley of California to collect continuous data suitable for eddy covariance (EC) flux calculations. The high time resolution $(5 \mathrm{~Hz})$ and high mass resolution (up to $5000 \mathrm{~m} / \Delta \mathrm{m}$ ) data from the PTRTOF-MS provided the basis for calculating the concentration and flux for a wide range of volatile organic compounds (VOC). Throughout the campaign, 664 mass peaks were detected in mass-to-charge ratios between 10 and 1278. Here we present PTR-TOF-MS EC fluxes of the 27 ion species for which the vertical gradient was simultaneously measured by PTR-MS. These EC flux data were validated through spectral analysis (i.e., co-spectrum, normalized co-spectrum, and ogive). Based on inter-comparison of the two PTR instruments, no significant instrumental biases were found in either mixing ratios or fluxes, and the data showed agreement within $5 \%$ on average for methanol and acetone. For the measured biogenic volatile organic compounds (BVOC), the EC fluxes from PTR-TOF-MS were in agreement with the qualitatively inferred flux directions from vertical gradient measurements by PTR-MS. For the
\end{abstract}

27 selected ion species reported here, the PTR-TOF-MS measured total $(24 \mathrm{~h})$ mean net flux of $299 \mu \mathrm{g} \mathrm{C} \mathrm{m}^{-2} \mathrm{~h}^{-1}$. The dominant BVOC emissions from this site were monoterpenes $(m / z 81.070+m / z 137.131+m / z$ 95.086, $\left.34 \%, 102 \mu \mathrm{g} \mathrm{m}^{-2} \mathrm{~h}^{-1}\right)$ and methanol $(\mathrm{m} / z 33.032,18 \%$, $\left.72 \mu \mathrm{g} \mathrm{C} \mathrm{m}^{-2} \mathrm{~h}^{-1}\right)$. The next largest fluxes were detected at the following masses (attribution in parenthesis): $\mathrm{m} / \mathrm{z}$ 59.048 (mostly acetone, $12.2 \%, 36.5 \mu \mathrm{g} \mathrm{C} \mathrm{m}{ }^{-2} \mathrm{~h}^{-1}$ ), $\mathrm{m} / \mathrm{z}$ 61.027 (mostly acetic acid, $11.9 \%, 35.7 \mu \mathrm{g} \mathrm{C} \mathrm{m}^{-2} \mathrm{~h}^{-1}$ ), $\mathrm{m} / z$ 93.069 (para-cymene + toluene, $4.1 \%, 12.2 \mu \mathrm{g} \mathrm{C} \mathrm{m}^{-2} \mathrm{~h}^{-1}$ ), $\mathrm{m} / \mathrm{z} \quad 45.033$ (acetaldehyde, $3.8 \%, \quad 11.5 \mu \mathrm{g} \mathrm{C} \mathrm{m}^{-2} \mathrm{~h}^{-1}$ ), $\mathrm{m} / \mathrm{z} 71.048$ (methylvinylketone + methacrolein, $2.4 \%$, $7.1 \mu \mathrm{g} \mathrm{m}^{-2} \mathrm{~h}^{-1}$ ), and $\mathrm{m} / \mathrm{z} 69.071$ (isoprene +2 -methyl3-butene-2-ol, $\left.1.8 \%, 5.3 \mu \mathrm{g} \mathrm{C} \mathrm{m}{ }^{-2} \mathrm{~h}^{-1}\right)$. Low levels of emission and/or deposition ( $<1.6 \%$ for each, $5.8 \%$ in total flux) were observed for the additional reported masses. Overall, our results show that EC flux measurements using PTR-TOFMS is a powerful new tool for characterizing the biosphereatmosphere exchange including both emission and deposition for a large range of BVOC and their oxidation products. 


\section{Introduction}

Quantifying both emission and deposition of atmospheric volatile organic compounds (VOC) and their oxidation products is critical in understanding their roles in tropospheric chemistry, particularly their contributions to photochemical production of ozone $\left(\mathrm{O}_{3}\right)$ and secondary organic aerosol (SOA) (Chameides et al., 1988; Andreae and Crutzen, 1997; Fuentes et al., 2000; Jang et al., 2002; Goldstein and Galbally, 2007). Ozone and aerosols affect human health, plant health, regional air quality and Earth's climate. On the global scale, biogenic volatile organic compounds (BVOC) emissions from vegetation are estimated to be an order of magnitude larger than those from fossil fuel combustion, so BVOC emissions constitute approximately $90 \%$ of global VOC emissions (Guenther et al, 1995). Emission rates of BVOC remain unknown for many potentially important plant species due to lack of measurements, and agricultural crops represent an area of significant uncertainty (Ormeño et al., 2010). The full range of BVOC emitted from any plant or ecosystem may also be poorly constrained due to instrumental limitations in existing data sets. Moreover, in present BVOC emission models such as the Biogenic Emission Inventory System (BEIS, Pierce et al., 1998) and the Model of Emissions of Gases and Aerosols from Nature (MEGAN, Guenther et al., 2006), there are additional uncertainties for example in estimating the VOC fluxes by up-scaling from leaf-level measurements to the ecosystem or landscape scale. A few studies have shown discrepancies between branch enclosure and canopy scale BVOC measurements. For example, Bouvier-Brown et al. (2009) and Ciccioli et al. (1999) detected much less emission of sesquiterpenes above plant canopies compared to the amount measured from branch enclosure tests, revealing significant losses of the sesquiterpenes before they escape the plant canopy due to their high reactivity.

Even larger uncertainties exist in the ultimate fate of atmospheric VOC, which must be oxidized until they form $\mathrm{CO}, \mathrm{CO}_{2}$, or secondary aerosol, or are removed from the atmosphere by wet or dry deposition (Goldstein and Galbally, 2007). Understanding of VOC deposition is particularly uncertain due to a lack of direct flux measurements, yet this loss process has been inferred to dominate the removal of VOC from the atmosphere (Hallquist et al., 2009). Recently, Karl et al. (2010) and Tani et al. (2010) have reported that some oxygenated VOC (OVOC), either directly emitted or formed from VOC oxidation in the atmosphere, are measurably deposited to plant ecosystems.

The eddy-covariance method is widely considered the most reliable and direct method to determine ecosystem scale fluxes for trace gases and is being widely applied to determine $\mathrm{CO}_{2}$ and $\mathrm{H}_{2} \mathrm{O}$ exchange between the atmosphere and biosphere (Baldocchi et al., 1988; Dabberdt et al., 1993; Baldocchi, 2003). The method requires a sensor which has very fast response (e.g., 5-20 Hz) and high sensitivity (Businger and Delany, 1990). For BVOC flux measurements using the EC method, the first field experiment was conducted by Shaw et al. (1998) and Guenther and Hills (1998); respectively, they measured acetone and formic acid fluxes over grassland using a trace atmospheric gas analyzer (TAGA) and isoprene fluxes over an oak forest using a chemiluminescence sensor. The development of the fast-response proton transfer reaction-mass spectrometer (PTR-MS) was a major advance in capability for BVOC EC flux measurements, but this instrument allowed flux measurements simultaneously for relatively few compounds because of limitations of the quadrupole mass filter (Karl et al., 2002).

Recently, a proton transfer reaction - time of flight - mass spectrometer (PTR-TOF-MS) has been developed which can measure an unprecedented number of BVOC simultaneously with very high time resolution, breaking through instrumental and technical limitations (Jordan et al., 2009; Graus et al., 2010). The new instrument allows simultaneous measurement of an unprecedented range of BVOC emissions to the atmosphere while also observing their oxidation products and deposition. The first EC measurements of BVOC using PTR-TOF-MS were previously reported over a grassland. This work was focused on comparing methanol (Muller et al., 2010) and monoterpenes (Bamberger et al., 2011) measured with PTR-MS, and analyzing the EC flux data from PTR-TOF-MS (Ruuskanen et al., 2011).

In this study, we report the first PTR-TOF-MS EC measurements above a tree ecosystem and intensively validate the appropriateness of EC flux measurements using PTRTOF-MS by comparing with EC fluxes and vertical gradient measurements from PTR-MS. To do that, a PTR-TOF-MS and a conventional PTR-MS were deployed simultaneously to collect continuous BVOC data for one month over an orange orchard in the Central Valley of California. The high time resolution $(5 \mathrm{~Hz})$ and high mass resolution (up to 5000 $\mathrm{m} / \Delta \mathrm{m}$ ) data from the PTR-TOF-MS provided the basis for determining concentrations and fluxes for the full range of VOC. We validate BVOC fluxes from the PTR-TOF-MS for select species (27 masses) by comparing them with data from the conventional PTR-MS (EC flux for five species and vertical gradient measurements for 21 species), and then discuss total VOC fluxes for the selected species.

\section{Experiment}

\subsection{Measurement site}

BVOC concentration and flux measurements by PTR-TOFMS and PTR-MS were made from 25 June to 26 July in 2010 as part of a one-year continuous field campaign (October 2009-November 2010) in an orange orchard in the Central Valley of California. The measurement site was a private orchard located $3 \mathrm{~km}$ west of the University of California Lindcove Research and Extension Center in 
Exeter $\left(36^{\circ} 21^{\prime} 23.68^{\prime \prime} \mathrm{N}\right.$ and $119^{\circ} 5^{\prime} 32.14^{\prime \prime} \mathrm{W}, 131 \mathrm{~m}$ above sea level). A detailed site description is given by Fares et al. (2012b). Briefly, this area features a Mediterraneantype climate with warm and dry summers; no rain was observed during the measurement period and the temperature remained within the range of $16-40^{\circ} \mathrm{C}$. Winds were predominantly westerly during the day and easterly at night. During the daytime (10:00-14:00 PST; Pacific Standard Time) footprints were mostly $(>90 \%)$ within the orchard block of "Valencia" orange trees (mean tree height $\sim 3.7 \mathrm{~m}$ ). The nighttime footprints (22:00-02:00 PST) were more varied with contributions from a combination of different citrus tree species in the surrounding orchard blocks (i.e. Valencia orange + Parent Navel orange (41\%), Valencia orange + Murcott mandarin $(38 \%)$, and Valencia orange + Parent Navel orange + Murcott mandarin $(21 \%)$. A $9.8 \mathrm{~m}$ telescoping tower was erected on the site holding meteorological sensors and gas sample inlets for measuring vertical gradients and fluxes of trace gases (e.g., $\mathrm{O}_{3}, \mathrm{CO}, \mathrm{CO}_{2}, \mathrm{H}_{2} \mathrm{O}$, and VOC). All the trace gas measurement instrumentation was housed in a temperature-controlled field laboratory.

\subsection{Instrumentation}

The PTR-TOF-MS and the standard PTR-MS were deployed simultaneously to collect VOC mixing ratio data suitable for applying eddy covariance flux calculations and for investigating vertical gradients. The basic principle of both instruments has been described elsewhere in detail (for PTRMS: Lindinger et al., 1998; de Gouw and Warneke, 2007; for PTR-TOF-MS: Jordan et al., 2009; Graus et al., 2010). Specifics of instrumental setup for this field experiment are given below. In addition, two 3-D sonic anemometers (Applied Technologies, Inc., Boulder, CO) were mounted on the tower at $7.1 \mathrm{~m}$ and $9.2 \mathrm{~m}$ above ground level to measure wind speed and temperature; the $10 \mathrm{~Hz}$ data were recorded by a data logger (CR3000, Campbell Scientific Inc., Logan, UT).

VOC mixing ratios were measured by PTR-TOF-MS through 2 individual gas sample inlets at $7.1 \mathrm{~m}$ (Fig. 1). For the first half (0-30 min) of each hour, a $15 \mathrm{~m}$ PFA tube (I.D. $\sim 4 \mathrm{~mm}$ ) was used to sample the ambient air from the tower. The tube was heated to $\sim 50^{\circ} \mathrm{C}$, and a sample flow of $10 \mathrm{~L} \mathrm{~min}^{-1}$ was maintained by a mass flow controller (MKS Instruments). This inlet was located next to the 3-D sonic anemometer and shared with the standard PTR-MS. During the second half (30-60 min) of each hour, the air was sampled through a $10 \mathrm{~m}$ coated stainless steel tube (I.D. $\sim 1 \mathrm{~mm}$, Restek sulfinert coating) heated $\sim 150^{\circ} \mathrm{C}$ to prevent wall loss of VOC. Both inlets were protected by particle filters (Teflon filter with PFA holder, PTFE membrane, pore size $2 \mu \mathrm{m}$ ), which were replaced every 2 weeks. In this paper, we will focus on flux data from the first half hour for PTR-TOFMS. During the whole campaign period, the drift tube of the PTR-TOF-MS was operated at a temperature of $120^{\circ} \mathrm{C}$, a drift voltage of $600 \mathrm{~V}$, and a pressure of $2.2-2.4 \mathrm{hPa}$. These

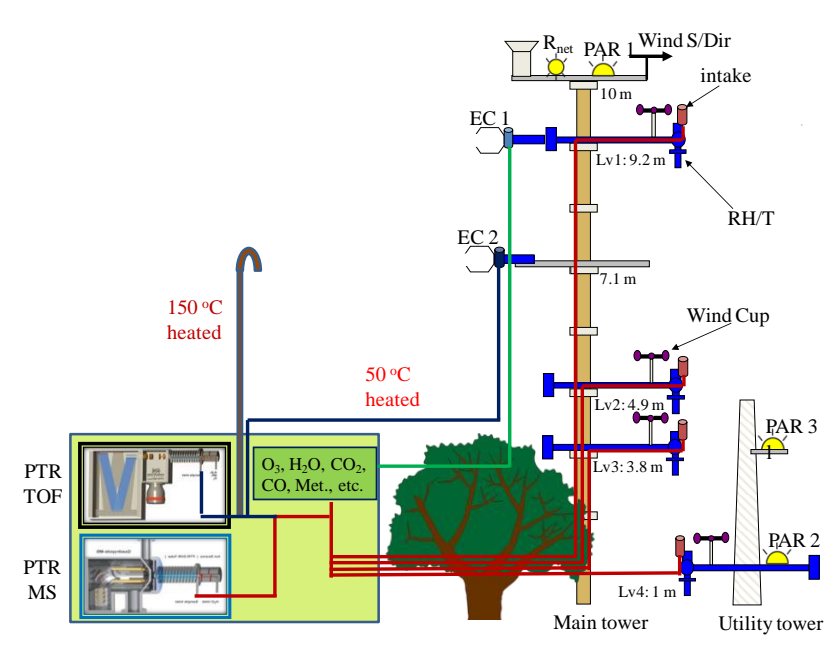

Fig. 1. Schematic diagram of PTR-TOF-MS and PTR-MS flux and vertical gradient measurement setup. The inlet at $7.1 \mathrm{~m}$ (EC 2) was shared by PTR-TOF-MS and PTR-MS for flux measurements during the first $30 \mathrm{~min}$ of each hour. Vertical gradients were measured with the PTR-MS for the second 30 min of each hour sequentially at four heights (Lv 1-4) while the PTR-TOF-MS sampled from the $150^{\circ} \mathrm{C}$ heated inlet located at $7.1 \mathrm{~m}$.

conditions correspond to an $E / N$ (electric field to number density of air ratio) value of $\sim 150 \mathrm{Td}$. To apply the eddy covariance method, high time resolution data (e.g. 5-20 Hz) are required. Therefore, ions were pulsed every $60 \mu$ s into the time-of-flight region, and detected by the Multi Channel Plate (MCP) at $0.2 \mathrm{~ns}$ resolution (5 GHz) resulting in 299499 bins per spectrum, allowing detection of an $\mathrm{m} / \mathrm{z}$ (mass-tocharge ratio) range from 10 to $1278 \mathrm{Da}$. By co-adding 3333 initial mass spectra, collection of $5 \mathrm{~Hz}$ data ( 1 cycle per $0.2 \mathrm{~s}$ ) was achieved and 900 cycle data were stored every $3 \mathrm{~min}$ in the compressed HDF5 format. Data processing to determine mass peaks was done by the IDL routine which has been developed and described in detail by Holzinger et al. (2010a). In total, 664 mass peaks with significant signal above the background noise were identified during this campaign.

For PTR-MS VOC measurements, the first half of each hour (0-30 $\mathrm{min})$ was used to measure fluxes of 5 masses $(\mathrm{m} / \mathrm{z} 33,59,69,81$, and 113$)$ by sharing the same inlet with PTR-TOF-MS at $7.1 \mathrm{~m}$. The dwell time on each mass was $0.2 \mathrm{~s}$; thus, one cycle of measurements including the primary ion signal $(\mathrm{m} / \mathrm{z} 21$ and 37) and several analog input channels were completed in $\sim 1.1 \mathrm{~s}$ (Fig. 2). An additional 4 inlets were used sequentially for 6 min each during the second half (30-60 min) of each hour (Fig. 2). These inlets, within (1.0 $\mathrm{m}$ and $3.76 \mathrm{~m})$ and above $(4.85 \mathrm{~m}$ and $9.18 \mathrm{~m})$ the canopy, were used to sample vertical gradients of 21 species $(\mathrm{m} / \mathrm{z})$ including the masses selected for the flux measurements (Fares et al., 2012a). The gradient inlets were identically designed ( $\sim 20 \mathrm{~m}$ PFA tubing, ID $\sim 4 \mathrm{~mm}$, sample flow of $10 \mathrm{~L} \mathrm{~min}^{-1}$ ) and continuously flushed at all times. The gradient measurement dwell times were one second per $m / z$, and 13 cycles per 


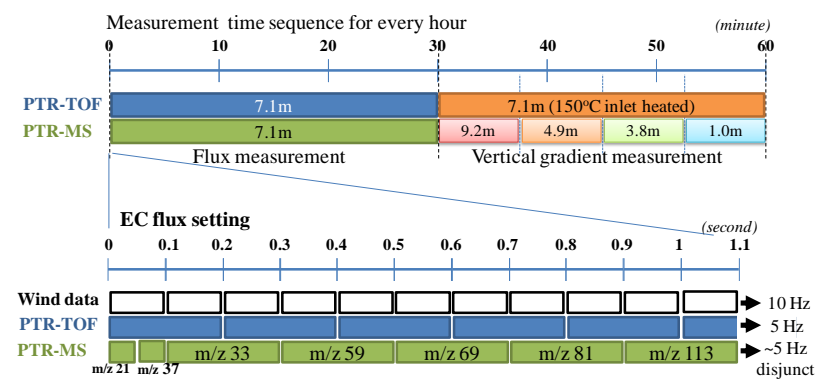

Fig. 2. Data acquisition sequence for the PTR-TOF-MS, PTR-MS, and 3-D sonic anemometer. The upper panel shows the hourly measurement scheme. The lower panel describes the data collecting sequence of one cycle corresponding to 1.1 seconds, which was repeated for first $30 \mathrm{~min}$ of each hour to measure fluxes. Data from the sonic anemometer and PTR-TOF-MS were collected at $10 \mathrm{~Hz}$ and $5 \mathrm{~Hz}$, respectively. PTR-MS flux data $(\mathrm{m} / z$ 33, 59, 69, 81 and 113) were sampled with dwell times of 0.2 seconds (overall $5 \mathrm{~Hz}$ disjunct) after collecting the primary ion signal $(\mathrm{m} / z, 21$ and 37) for the first $0.1 \mathrm{~s}$.

height level were averaged to form hourly values. The PTRMS instrument was maintained at an $E / N$ ratio of $\sim 128 \mathrm{Td}$ (drift tube temperature: $45^{\circ} \mathrm{C}$, voltage: $600 \mathrm{~V}$, pressure: $2.0-$ $2.2 \mathrm{hPa}$ ).

Instrumental background and calibration measurements were performed automatically two times per day $(02: 30$ 03:00 and 15:30-16:00 PST). The instrumental background was determined by measuring zero air produced from ambient air purified by passing through a catalytic converter (stainless steel tube filled with platinum-coated quartz wool) at $350^{\circ} \mathrm{C}$. Dilutions $(10-50 \mathrm{ppb})$ of gravimetrically mixed gas-standards of methanol, acetaldehyde, acetone, isoprene, methyl-vinyl-ketone, benzene, hexenal, hexanal, and d-limonene (Apel \& Riemer) were regularly measured to provide calibration in both instruments. Concentrations for compounds which were not calibrated with gas standards were calculated using default reaction rate constants $\left(3 \times 10^{-9} \mathrm{~cm}^{3} \mathrm{~s}^{-1}\right.$ molecule $\left.{ }^{-1}\right)$, measured transmission efficiencies, and calculated reaction times. The transmission efficiency of both mass spectrometers were measured from $\mathrm{m} / \mathrm{z} 33$ to $\mathrm{m} / \mathrm{z} 219$ using a gas standard mixture of methanol, acetonitrile, acetaldehyde, acetone, methylvinyl-ketone, benzene, toluene, xylene, trifluorobenzene, bromobenzene, trichlorobenzene, and iodotoluene at concentrations of $\sim 100 \mathrm{ppb}$ each (Apel \& Riemer). During the measurement period, the averaged sensitivities for PTR-TOF-MS ranged between 8 and $36 \mathrm{ncpspbv}^{-1}$, similar to that reported by Ruuskanen et al. (2011). For PTR-MS, the sensitivity to each measured compound has been reported by Fares et al. (2012a). Calculation of VOC volume mixing ratios using transmission factors and reaction rate constants was done according to the method described in Holzinger et al. (2010b).

\subsection{Flux calculation using the eddy covariance (EC) method}

Flux calculation for the PTR-MS was based on the continuous flow disjunct eddy covariance method following Davison et al. (2009) and described elsewhere in detail (Fares et al., 2012a).

For PTR-TOF-MS, we applied the following method to calculate EC fluxes for all identified mass peaks:

1. Data preparation: 8000 cycles of the $5 \mathrm{~Hz}$ VOC data (corresponding to minutes 3.3-30 of each hour) were used for EC calculations. Even though the evaluated period was thus $\sim 26.7 \mathrm{~min}$, for readability we refer to these periods as $30 \mathrm{~min}$ fluxes. The $10 \mathrm{~Hz}$ wind data from minute $0-30$ of each hour were reduced to $5 \mathrm{~Hz}$ data that matched the VOC sampling time.

2. Data de-spiking and gap-filling: the VOC and wind data files contained spikes (typically $0-15$ per $30 \mathrm{~min}$ ) which were due to electronic noise and/or unidentified software malfunctions. These spikes were removed by deleting data points exceeding 10 times the standard deviation of the 8000 point dataset. In addition, saving of the 3 min data files on the hard disk caused gaps of durations up to one second. All these gaps were filled with mean values of the 20 neighboring data points (before $\&$ after).

3. Wind data rotation: horizontal and vertical wind data for all flux periods were rotated according to a planar fit technique which forces the mean vertical wind speed to equal 0 (Wilczack et al., 2001).

4. Lag time correction between 3-D sonic anemometer and PTR-TOF-MS: the lag times were determined by checking the cross-correlation of vertical wind speed with VOC data by shifting wind data in steps of $0.2 \mathrm{~s}$ (data time resolution). The lag time was determined as the time shift which maximized the cross-correlation coefficient. All 30 min flux data between 10:00 and 16:00 PST were evaluated. Because the internal clocks of the PTR-TOF-MS computer and the data logger differed slightly, the lag times varied between $9.2 \mathrm{~s}$ and $17.8 \mathrm{~s}$ during the course of the campaign. However, no abrupt shifts were observed during periods of continuous operation. The following lag times were applied (for continuous measurement periods): $9.2 \mathrm{~s}$ (26-29 June), 14.6 s (2-10 July), 17.8 s (11-13 July), 16.6 s (14-21 July), and $17.4 \mathrm{~s}$ (22-26 July). Figure 3 shows average daytime cross correlations for five lag time corrected compounds.

5. EC flux calculation: fluxes of BVOC $\left(F_{\mathrm{wc}}, \mathrm{nmol} \mathrm{m}^{-2} \mathrm{~s}^{-1}\right)$ were calculated using the EC method in which the vertical fluxes of BVOC are determined by the mean covariance between deviations 


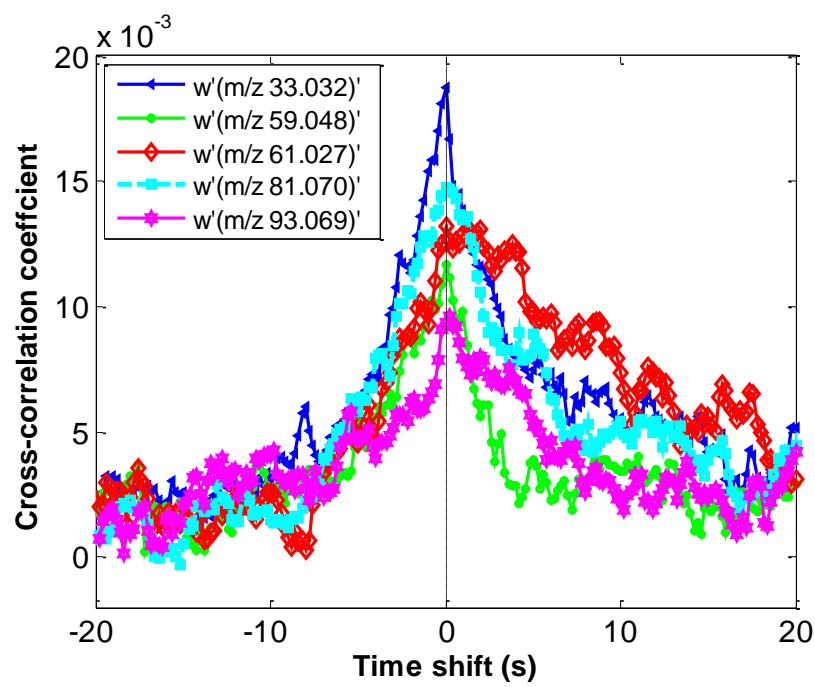

Fig. 3. Cross-correlation plots of vertical wind speed and concentration for the five most dominant flux compounds $(m / z$ 33.032, 59.048, 61.027, 81.070 and 93.069) observed by PTR-TOF-MS, averaged over 10:00-16:00 PST throughout the whole measurement campaign.

of the vertical wind speed and each BVOC mixing ratio for each $30 \mathrm{~min}$ period,

$$
F_{\mathrm{wc}}=\frac{\sigma}{N} \sum_{i=1}^{N}\left(w_{i}-\bar{w}\right) \cdot\left(c_{i}-\bar{c}\right)=\frac{\sigma}{N} \sum_{i=1}^{N} w_{i}^{\prime} \cdot c_{i}^{\prime}
$$

where $\sigma$ is the air density $\left(\mathrm{mol} \mathrm{m}^{-3}\right), N$ is the total number of data points in each 30 min measurement period, and $w_{i}-\bar{w}$ or $w_{i}^{\prime}$ is the instantaneous deviation of the vertical wind speed from its average, and $c_{i}-\bar{c}$ or $c^{\prime}$ is the instantaneous deviation of the BVOC mixing ratio from its average (nmol mol ${ }^{-1}$ or ppbv). We did not apply de-trending procedures since linear or non-linear de-trending can remove real fluxes; therefore, we used only block averaging for each flux period.

6. Flux data filtering: we discarded data to insure more robust results if (i) the tilt angle from rotating the vertical wind data exceeded $5^{\circ}$ or (ii) the flux data did not comply with our stationarity criterion. To evaluate the stationarity, we divided each $30 \mathrm{~min}$ flux period into 5 segments, calculating the EC flux for each segment, and comparing the average of the five segments to the EC flux for the full $30 \mathrm{~min}$ period. The measurement was discarded if the difference between these two quantities was larger than $30 \%$ (Lee et al., 2004; Foken and Wichura, 1996). For all the BVOC observed, 55-85\% of daytime and $30-65 \%$ of nighttime data complied with these criteria.

7. Flux error estimation: the potential errors in flux estimation are summarized in Table 1. Briefly, uncertain- ties in EC flux may include systematic errors due to (i) sensor separation, (ii) inlet dampening, (iii) insufficient instrument time response, (iv) uncertainties in concentration determinations, or (v) random noise in the EC flux.

Sensor separation errors are caused by different sampling positions for the sonic anemometer and ambient sample inlet of the PTR-TOF-MS resulting in a flux underestimation which can be estimated using a transfer function (Moore, 1986):

$T_{\mathrm{S}}(f)=e^{-9.9\left(\frac{f \cdot s}{U}\right)^{1.5}}$

where $f$ is the cospectral frequency $(\mathrm{Hz}), s$ is the sensor separation distance $(\mathrm{m})$ and $U$ is mean horizontal wind speed $\left(\mathrm{m} \mathrm{s}^{-1}\right)$. During the campaign, the inlet was located laterally $0.1 \mathrm{~m}$ away from the sonic anemometer, so for the observed range of wind speeds $(0.5-3.5$ $\mathrm{m} \mathrm{s}^{-1}$ ), this error should be less than $2 \%$ of the flux.

Inlet dampening errors are due to attenuation of small mixing ratio fluctuations when sampling through a tube. Flux underestimation from inlet dampening is typically evaluated using a transfer function (Massman, 1991):

$T_{\mathrm{S}}(f)=e^{-\frac{4 \pi^{2} \Lambda a L f^{2}}{u^{2}}}$

where $\Lambda$ is the attenuation parameter (assuming $\sim 4.2$ at $R e \sim 3400$ for $\left.\mathrm{CH}_{4}\right), L$ and $a$ are length (15 m) and inner radius $(0.002 \mathrm{~m})$ of the sampling tube and $u$ is mean tube flow velocity $\left(14.7 \mathrm{~m} \mathrm{~s}^{-1}\right)$. We estimate an error $(<0.15 \%)$ due to this effect assuming similar VOC characteristics with $\mathrm{CH}_{4}$. However, this error estimate is probably not representative for most VOC. Especially some condensable and/or sticky compounds such as acetic acid may suffer from much larger dampening errors. For better estimates we would need to characterize the attenuation parameters for all individual compounds. We discuss further about the inlet dampening of fluctuations for condensable or sticky species causes a systematic underestimate of the flux in Sect. 3.2 for acetic acid $(m / z$ 61.027).

Flux errors also can be caused by insufficient instrument time response to small fluctuations contributing to the flux, and this error can be approximated by a transfer function (Horst, 1997):

$T_{\mathrm{S}}(f)=\frac{1}{1+(2 \pi f \tau)^{2}}$

where, $\tau$ is the time response $(0.1 \mathrm{~s})$ of the instrument, and we estimate this error is $\sim 0.25 \%$ for our measurements.

In addition, flux estimation errors arise from instrument noise which may correlate with vertical wind speed and 
Table 1. Possible source specific flux estimation errors.

\begin{tabular}{lll}
\hline Source of error & Bias & Estimated error \\
\hline Sensor separation & Underestimation & $<2 \%$ \\
High frequency damping & Underestimation & $<0.15 \%$ \\
Instrumental response time & Underestimation & $0.25 \%$ \\
Random noise & None & $0.1-16 \%$ a \\
Concentration estimation & None & $<30 \%($ or $<20 \%$ b) \\
$\mathrm{H}_{2} \mathrm{O}$ and density fluctuation & Underestimation for deposition flux & $<5 \%$ \\
& Overestimation for emission flux & $<4 \%$ \\
\hline
\end{tabular}

a Based on daytime (10:00-14:00 PST) species specific errors.

$\mathrm{b}$ The error of the species calibrated with a standard gas is less than $20 \%$.

is estimated by (Lenschow and Kristensen, 1985; Ritter et al., 1990; Farmer et al., 2006):

$$
\sigma_{\text {inst }}^{2}=\frac{\sigma_{\mathrm{w}}^{2} \sigma_{\mathrm{n}}^{2} \Delta t}{T}
$$

where $T$ is the time length of a sample ( $30 \mathrm{~min}), \sigma_{\mathrm{w}}$ and $\sigma_{\mathrm{n}}$ are the variance of the vertical wind speed and the instrument noise, and $\Delta t$ is the sampling interval $(0.2 \mathrm{~s})$. For the PTR-TOF-MS, instrument noise is described by a Poisson distribution: the $1 \sigma$ error in a measurement that is derived from counting a total of $N$ ions is $\sqrt{N}$ (de Gouw and Warneke, 2007), so $\sigma_{\mathrm{n}}$ can be calculated in concentration units using the instrument sensitivity for each flux period. Daytime (10:00-14:00 PST) flux uncertainty based on this random error varied by compound from $0.1 \%$ to $16 \%$.

Uncertainties in the flux also can arise from systematic errors in concentration determination. The accuracy for compounds calibration using known gas standards is better than $20 \%$. For all other compounds the concentration has been estimated using calculated values for the collision rate constant which should equal the reaction rate constant within $\pm 30 \%$ (Holzinger et al., 2010a).

The possible error due to air density fluctuation related to $\mathrm{H}_{2} \mathrm{O}$ concentration change (so called WPL correction) is also estimated (Lee et al., 2004). Here, we only considered $\mathrm{H}_{2} \mathrm{O}$ effects since the PTR-TOF-MS is a closed-path sensor and the sampling line temperature and instrument temperature were controlled. Ignoring this correction could potentially cause overestimations $(<5 \%)$ in deposition fluxes and underestimations $(<4 \%)$ in emission fluxes under the assumption that all species are non-soluble. However, we did not correct for $\mathrm{H}_{2} \mathrm{O}$ effects in our estimated fluxes because we consider this potential error to be minor, it would not affect the direction of the fluxes, and each compound may be subject to different additional $\mathrm{H}_{2} \mathrm{O}$ effects that vary with solubility (e.g. desorption from the wall). Further investigations into the hygroscopic properties of each com- pound would be needed to elucidate possible additional errors.

For compounds with bi-directional fluxes, defining a flux detection limit is challenging. In order to detect bidirectional fluxes, we examined the absolute value of the cross correlation. We considered the flux detectable for compounds with an absolute value cross correlation (around zero time shift) at least three times the standard deviation of the noise of the absolute value cross correlation over time shifts of $\pm 20 \mathrm{~s}$. For compounds that had both deposition and emission, fluxes measured by PTR-TOF-MS, and vertical gradients by PTR-MS, we were also able to independently confirm that measured deposition occurred simultaneously with gradients that also indicated deposition, as demonstrated for methanol in Fig. 8a and c.

\section{Results and discussion}

\subsection{Flux and mixing ratio}

A total of 664 mass peaks with significant signal above the noise were identified by IDL routines according to Holzinger et al. (2010a). These include major primary ions (e.g. $\left.\left(\mathrm{H}_{2} \mathrm{O}\right) \mathrm{H}^{+},\left(\mathrm{H}_{2} \mathrm{O}\right)_{2} \mathrm{H}^{+},\left(\mathrm{H}_{2} \mathrm{O}\right)_{3} \mathrm{H}^{+}\right)$, impurities such as $\mathrm{O}_{2}^{+}$, $\mathrm{NO}^{+}, \mathrm{N}_{2} \mathrm{H}^{+}$, and ammonium ions (e.g. $\mathrm{NH}_{3}^{+}, \mathrm{NH}_{3} \mathrm{NH}_{3} \mathrm{H}^{+}$). We applied the described flux routines to 555 peaks above $\mathrm{m} / \mathrm{z} 31$ (this includes protonated formaldehyde), excluding all above mentioned peaks. In this paper, we focus on 27 ion species including all those selected for PTR-MS flux and vertical gradient measurement, acetic acid $(m / z$ 61.027), and a major fragment of terpenes $(m / z$ 95.086) which showed significant flux.

In Table 2, the 27 selected ion species are listed by 24h (day/night) averaged mixing ratios and fluxes. Figure 4 shows the full time series and diurnal profiles of mixing ratios and fluxes measured by PTR-TOF-MS for methanol and acetone (monitored at $m / z 33.032$ and 59.048, respectively) which were the compounds with the highest mixing ratios measured at this site. The fluxes of BVOC directly emitted 
Table 2. Mixing ratio and flux information for 27 selected ion species.

\begin{tabular}{|c|c|c|c|c|}
\hline \multicolumn{2}{|c|}{ Mass to charge ratio $(\mathrm{m} / \mathrm{z})$} & \multirow{2}{*}{$\begin{array}{l}\text { Possible empirical } \\
\text { formulae and dominant } \\
\text { compound }^{\mathrm{a}}\end{array}$} & \multirow{2}{*}{$\begin{array}{l}\text { Typical Mixing Ratio } \\
{\left[\mathrm{nmol} \mathrm{mol}^{-1}\right]} \\
24 \text { h-mean(day/night) }\end{array}$} & \multirow{2}{*}{$\begin{array}{l}\text { EC Flux }{ }^{\mathrm{c}} \\
{\left[\mu \mathrm{g} \mathrm{Cm} \mathrm{C}^{-2} \mathrm{~h}^{-1}\right]} \\
24 \text { h-mean(day/night) }\end{array}$} \\
\hline PTR-MS & PTR-TOF-MS & & & \\
\hline 33 & 33.032 & $\begin{array}{l}\mathrm{CH}_{3} \mathrm{OHH}^{+}(-1.4) \\
\text { Methanol }\end{array}$ & $\begin{array}{l}19.89 \\
(16.85 / 24.55)\end{array}$ & $71.5(182.44 / 9.46)$ \\
\hline 42 & 42.033 & $\begin{array}{l}\mathrm{C}_{2} \mathrm{H}_{3} \mathrm{NH}^{+}(-1.0) \\
\text { Acetonitrile }\end{array}$ & $0.3(0.3 / 0.3)$ & $0(3.1 / 0.7)$ \\
\hline 45 & 45.033 & $\begin{array}{l}\mathrm{C}_{2} \mathrm{H}_{4} \mathrm{OH}^{+}(-0.9) \\
\text { Acetaldehyde }\end{array}$ & $2.91(2.68 / 3.28)$ & $11.5(38.6 / 3.4)$ \\
\hline 59 & 59.048 & $\begin{array}{l}\mathrm{C}_{3} \mathrm{H}_{6} \mathrm{OH}^{+}(-0.9) \\
\text { Acetone }\end{array}$ & $4.52(3.73 / 5.35)$ & $36.5(98.6 / 11.7)$ \\
\hline $61^{\mathrm{d}}$ & 61.027 & $\begin{array}{l}\mathrm{C}_{2} \mathrm{H}_{4} \mathrm{O}_{2} \mathrm{H}^{+}(-1.2) \\
\text { Acetic acid }\end{array}$ & $4.91(5 / 5.51)$ & $35.7(79.9 / 0.8)$ \\
\hline 69 & 69.071 & $\begin{array}{l}\mathrm{C}_{5} \mathrm{H}_{8} \mathrm{H}^{+}(0.8) \\
\text { Isoprene }+\mathrm{MBO}^{\mathrm{e}}\end{array}$ & $0.28(0.18 / 0.35)$ & $5.31(8.07 / 1.88)$ \\
\hline 71 & 71.048 & $\begin{array}{l}\mathrm{C}_{4} \mathrm{H}_{6} \mathrm{OH}^{+}(-0.8) \\
\mathrm{MVK}+\mathrm{MACR}^{\mathrm{f}}\end{array}$ & $0.3(0.2 / 0.36)$ & $7.05(14.8 / 2.31)$ \\
\hline 79 & 79.054 & $\begin{array}{l}\mathrm{C}_{6} \mathrm{H}_{6} \mathrm{H}^{+}(0.4) \\
\text { Benzene }\end{array}$ & $0.1(0.05 / 0.14)$ & $4.14(4.29 / 0.18)$ \\
\hline 81 & 81.070 & $\begin{array}{l}\mathrm{C}_{6} \mathrm{H}_{8} \mathrm{H}^{+}(0.1) \\
\text { Monoterpenes }\end{array}$ & $0.5(0.22 / 0.74)$ & $65.6(90.8 / 40.2)$ \\
\hline 83 & 83.086 & $\begin{array}{l}\mathrm{C}_{6} \mathrm{H}_{10} \mathrm{H}^{+}(0.6) \\
\text { Hexanal, Hexenols }\end{array}$ & $0.13(0.07 / 0.17)$ & $1.72(2.8 / 0.14)$ \\
\hline 87 & 87.077 & $\begin{array}{l}\mathrm{C}_{5} \mathrm{H}_{10} \mathrm{OH}^{+}(-3.7) \\
\mathrm{MBO}^{\mathrm{e}}\end{array}$ & $0.07(0.04 / 0.09)$ & $1.4(-1.3 / 0.2)$ \\
\hline 93 & 93.069 & $\begin{array}{l}\mathrm{C}_{7} \mathrm{H}_{8} \mathrm{H}^{+}(-0.8) \\
\begin{array}{l}\text { Toluene } \\
\text { cymene }\end{array}\end{array}$ & $0.14(0.04 / 0.22)$ & $12.2(25.5 / 4.4)$ \\
\hline $95^{\mathrm{d}}$ & 95.086 & $\begin{array}{l}\mathrm{C}_{7} \mathrm{H}_{10} \mathrm{H}^{+}(0.5) \\
\text { Monoterpenes }\end{array}$ & $0.25(0.16 / 0.33)$ & $20.1(32.6 / 15.0)$ \\
\hline 99 & 99.078 & $\begin{array}{l}\mathrm{C}_{6} \mathrm{H}_{10} \mathrm{OH}^{+}(-2.6) \\
\text { Hexenals }\end{array}$ & $0.04(0.02 / 0.05)$ & $1.42(3.29 / 0.01)$ \\
\hline \multirow[t]{2}{*}{107} & 107.049 & $\begin{array}{l}\mathrm{C}_{7} \mathrm{H}_{6} \mathrm{OH}^{+}(-0.1) \\
\text { Benzaldehyde }\end{array}$ & $0.05(0.01 / 0.09)$ & $1.65(5.78 / 0.29)$ \\
\hline & 107.085 & $\begin{array}{l}\mathrm{C}_{8} \mathrm{H}_{10} \mathrm{H}^{+}(-0.5) \\
\text { Xylene }\end{array}$ & $0.08(0.01 / 0.12)$ & $5.6(8.95 / 3.03)$ \\
\hline \multirow[t]{2}{*}{111} & 111.080 & $\begin{array}{l}\mathrm{C}_{7} \mathrm{H}_{10} \mathrm{OH}^{+}(-0.4) \\
\text { Unknown }\end{array}$ & $0.06(0.03 / 0.07)$ & $0.72(3.73 /-0.91)$ \\
\hline & 111.118 & $\begin{array}{l}\mathrm{C}_{8} \mathrm{H}_{14} \mathrm{H}^{+}(1.2) \\
\text { Unknown }\end{array}$ & $0.03(0.02 / 0.04)$ & $-1.24(-1.53 /-0.83)$ \\
\hline \multirow[t]{2}{*}{113} & 113.024 & $\begin{array}{l}\mathrm{C}_{5} \mathrm{H}_{4} \mathrm{O}_{3} \mathrm{H}^{+}(0.7) \\
\text { Unknown }\end{array}$ & $0.06(0.06 / 0.07)$ & $-0.01(-0.21 /-0.18)$ \\
\hline & 113.058 & $\begin{array}{l}\mathrm{C}_{6} \mathrm{H}_{8} \mathrm{O}_{2} \mathrm{H}^{+}(-1.7) \\
\text { Unknown }\end{array}$ & $0.05(0.03 / 0.06)$ & $-0.19(-3.18 /-0.52)$ \\
\hline 137 & 137.131 & $\begin{array}{l}\mathrm{C}_{10} \mathrm{H}_{16} \mathrm{H}^{+}(-1.5) \\
\text { Monoterpenes }\end{array}$ & $0.12(0.05 / 0.18)$ & $15.9(18.8 / 9.95)$ \\
\hline \multirow[t]{2}{*}{139} & 139.039 & $\begin{array}{l}\mathrm{C}_{7} \mathrm{H}_{6} \mathrm{O}_{3} \mathrm{H}^{+}(0) \\
\text { Unknown }\end{array}$ & $0.02(0.01 / 0.03)$ & $0.75(-0.96 / 0.66)$ \\
\hline & 139.110 & $\begin{array}{l}\mathrm{C}_{9} \mathrm{H}_{14} \mathrm{OH}^{+}(-1.7) \\
\text { Nopinone }\end{array}$ & $0.03(0 / 0.05)$ & $-0.15(1.71 /-0.88)$ \\
\hline 149 & 149.094 & $\begin{array}{l}\mathrm{C}_{10} \mathrm{H}_{12} \mathrm{OH}^{+}(-2.1) \\
\text { Methyl-chavicol }\end{array}$ & $0.02(0.01 / 0.04)$ & $-0.5(0.5 / 0.2)$ \\
\hline 151 & 151.109 & $\begin{array}{l}\mathrm{C}_{10} \mathrm{H}_{14} \mathrm{OH}^{+}(-2.7) \\
\text { Pinonaldehyde }\end{array}$ & $0.02(0.01 / 0.02)$ & $1.04(4.93 /-0.16)$ \\
\hline 155 & 155.137 & $\begin{array}{l}\mathrm{C}_{10} \mathrm{H}_{18} \mathrm{OH}^{+}(-6.0) \\
\text { Linalool }\end{array}$ & $0.01(0.01 / 0.01)$ & $0.1(1.1 / 0.09)$ \\
\hline 205 & 205.195 & $\begin{array}{l}\mathrm{C}_{15} \mathrm{H}_{24} \mathrm{H}^{+}(-0.1) \\
\text { Sesquiterpenes }\end{array}$ & $0.02(0.02 / 0.02)$ & $0.8(1.28 / 0.32)$ \\
\hline
\end{tabular}

a The difference between the measured mass and the exact ion mass in $\mathrm{mDa}$ is given in parenthesis. ${ }^{\mathrm{b}}$ Daytime and nighttime average is taken by each data during hour 10:00-14:00 and 22:00-02:00 PST, respectively. ${ }^{\mathrm{c}}$ Positive numbers represent emission from the surface, and negatives are deposition to the surface. ${ }^{\mathrm{d}}$ No measurement by the PTR-MS. ${ }^{\mathrm{e}}$ 2-methyl-3-butene-2-ol. ${ }^{\mathrm{f}}$ sum of methylvinylketone and methacrolein. 

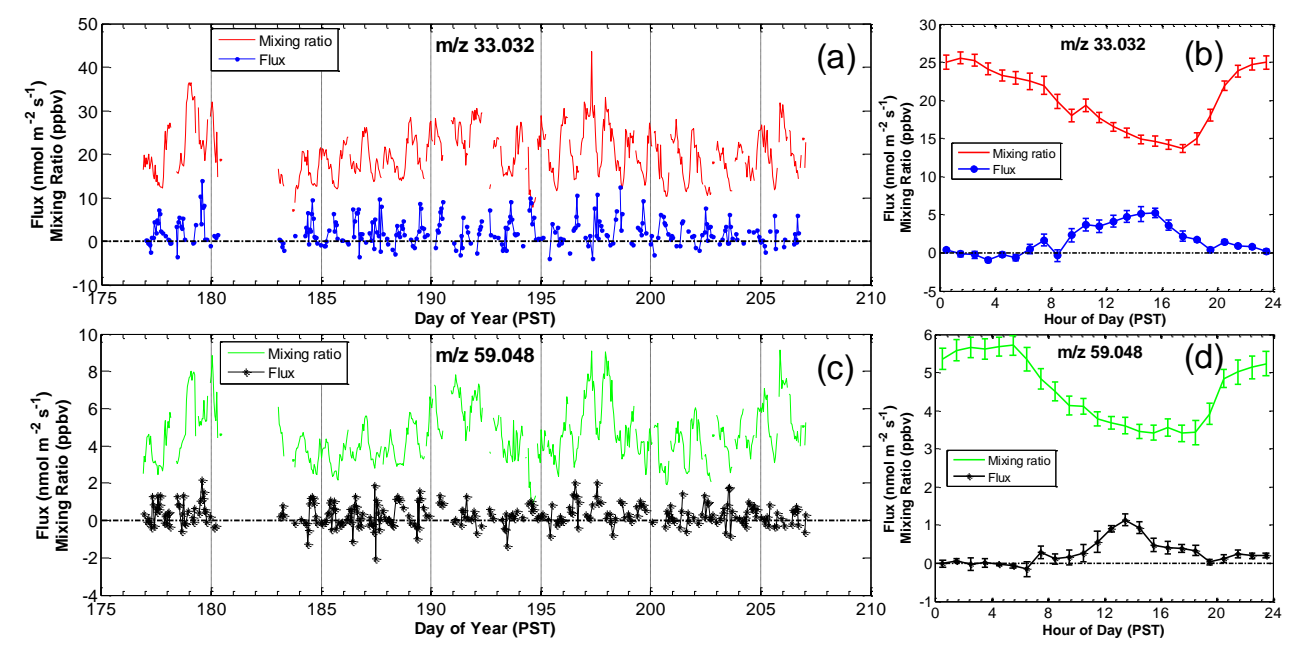

Fig. 4. Time series (26 June to 26 July 2012) of mixing ratios and fluxes for (a) $\mathrm{m} / z$ 33.032(methanol) and (c) $\mathrm{m} / \mathrm{z} 59.048$ (acetone) from PTR-TOF-MS measurements. Hourly averaged diurnal cycles of mixing ratios and fluxes of $\mathrm{m} / z .33 .032$ and $\mathrm{m} / \mathrm{z}$. 59.048 are shown in (b) and (d), respectively. Error bars in (b) and (d) denote standard errors of all measurements at the respective hour of the day.

by plants reached maxima in the afternoon when the temperature and light levels were highest and vertical turbulent mixing was fastest. However, mixing ratios were lower during daytime compared to nighttime for most BVOC including methanol, acetone, acetaldehyde, acetic acid, and monoterpenes. This was mainly due to the dilution of the emissions into a larger mixing layer and faster oxidation of BVOC during daytime. A detailed discussion of diurnal boundary layer dynamics in this area and season can be found in Bianco et al. (2011).

\subsection{Spectral analysis}

Spectral analysis provides a useful tool to validate the instrument's performance in both high and low frequency regimes. Here, we analyze fluxes of the 5 ion species $(\mathrm{m} / z$ 33.032: $\mathrm{CH}_{3} \mathrm{OHH}^{+}, m / z$ 59.048: $\mathrm{C}_{3} \mathrm{H}_{6} \mathrm{OH}^{+}, m / z$ 61.027: $\mathrm{C}_{2} \mathrm{H}_{4} \mathrm{O}_{2} \mathrm{H}^{+}, m / z$ 81.070: $\mathrm{C}_{6} \mathrm{H}_{8} \mathrm{H}^{+}, m / z$ 93.069: $\mathrm{C}_{7} \mathrm{H}_{8} \mathrm{H}^{+}$) showing the most significant fluxes at this site. The cospectra in Fig. 5a and $\mathrm{b}$ present the frequency distribution for vertical wind speed $(w)$ with sensible heat $(T)$ and 5 dominant BVOC. The data represent average daytime conditions (10:00-14:00 PST) for the entire measurement period. Generally, the fall-off slopes for the five compounds in the inertial sub-range (above $0.03 \mathrm{~Hz}$ ) follow a $-5 / 3$ slope similar to the sensible heat flux $\left(w^{\prime} T^{\prime}\right)$ (Fig. 5a and b) and demonstrates that the PTR-TOF-MS system provides adequate time response to measure EC flux. Co-spectra of $w^{\prime}(m / z \text { 59.048) })^{\prime}, w^{\prime}(m / z 61.027)^{\prime}, w^{\prime}(m / z$ 81.070)', and $w^{\prime}(m / z$ 93.069)' show some negative values (closed symbols) at high frequency above $0.3 \mathrm{~Hz}$, and this may indicate complex processes within and/or above the canopy such as fast photochemical loss/production oxidizing BVOC with wake turbulence production. A similar phenomenon was ob- served in other studies for peroxyacetyl nitrate and formaldehyde (Wolfe et al., 2009; DiGangi et al., 2011). For the co-spectrum of $w^{\prime}(m / z 61.027)^{\prime}$, loss of flux signal is apparent as successive fall-off of signal at frequencies around $\sim 0.06 \mathrm{~Hz}$. This loss of signal may be explained by dampening of fast fluctuations in the sample tube due to stickiness of acetic acid, and is consistent with cross-correlations with vertical wind speed compared to those of other compounds that are less sticky (Fig. 3). Co-spectra of $w^{\prime}(m / z$ 81.070)', and $w^{\prime}(m / z$ 93.069)' also demonstrate some loss of signal, but with different features (fall-off at different frequencies) than acetic acid, indicating loss processes may differ by chemical species.

Figure 5c and d show normalized co-spectra demonstrating that the dominant frequencies transporting flux are in the range $0.03-0.1 \mathrm{~Hz}$ for these 5 ion species, similar to the normalized co-spectrum of $w^{\prime} T^{\prime}$. The co-spectra of individual compounds exhibit slightly different patterns. For example, the frequency of maximum flux for $m / z 61.027$ is similar to other compounds, but it has a unique second maximum at low frequencies (around $0.003 \mathrm{~Hz}$ ) and a significant dip between 0.06 and $0.5 \mathrm{~Hz}$. In contrast, normalized co-spectra for $\mathrm{m} / z$ 33.032 and $m / z 59.048$ show small peaks at high frequency around $1 \mathrm{~Hz}$. It is apparent from these comparisons that individual compounds have different eddy features that must result from differences in sources and sinks such as leaf/soil emission, photochemical production or loss at different time scales, or surface removal by degree of stickiness/solubility. These different features could potentially result from uncharacterized instrument noise, but most eddy features are reproducible so we consider noise an unlikely source. For example, for acetone these features (peaks at $0.03-0.1 \mathrm{~Hz}$ and $1 \mathrm{~Hz}$ ) typically show up in the normalized co-spectrum of 

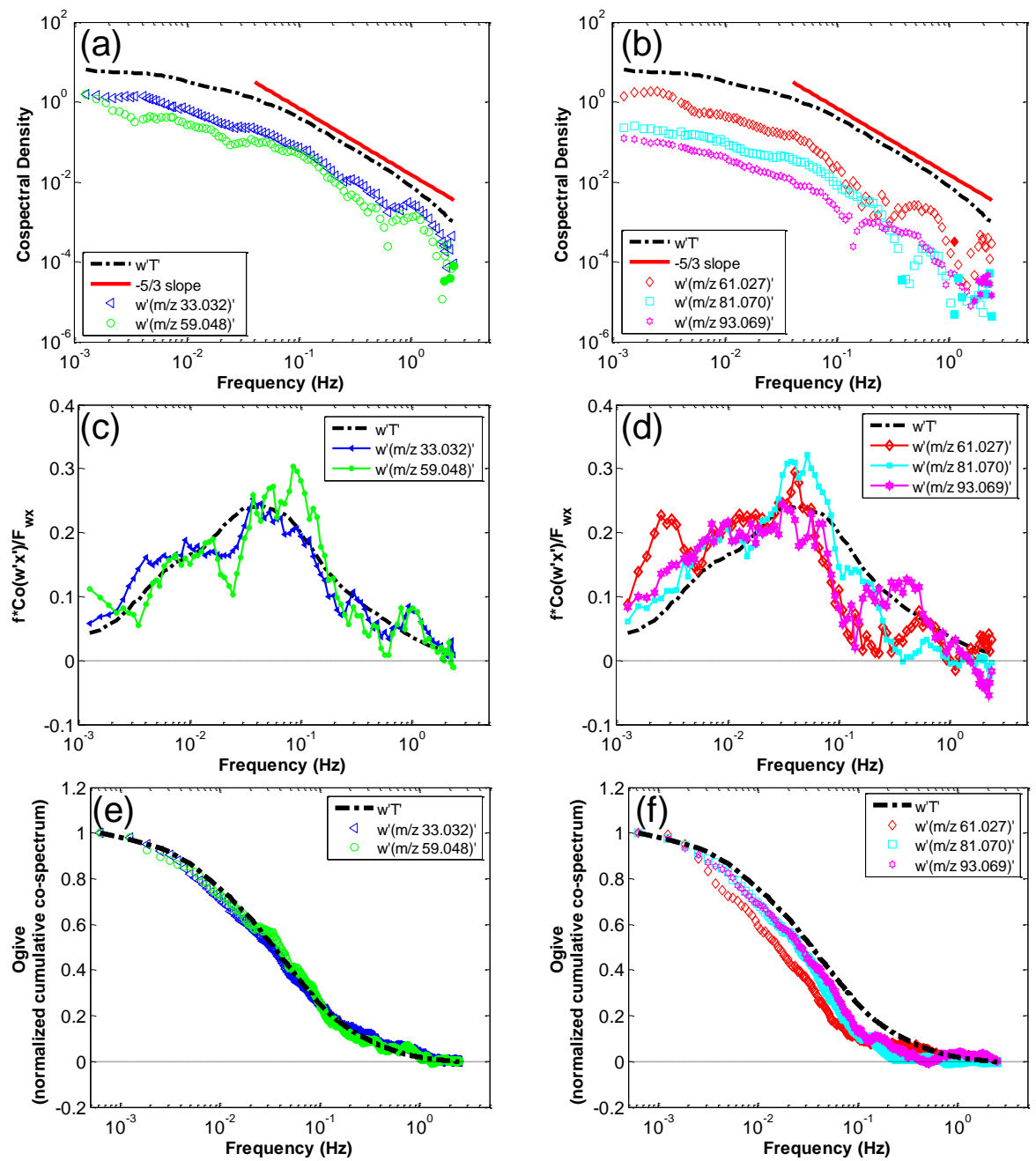

Fig. 5. Cospectral density (a, b), frequency weighted covariance normalized cospectra (c, d), and normalized cumulative cospectra or ogive (e, f), of five dominant BVOC (colored open symbols) and sensible heat (black broken line) binned into 100 evenly spaced intervals along the frequency axis. Each closed symbol in (a) and (b) represents negative values.

individual 30 min periods (Fig. 7a). Therefore, we think this difference is a real characteristic of individual compounds, not instrument noise.

Normalized cumulative distributions of the co-spectra, commonly referred to as ogives, are shown in Fig. 5e and f. Comparing to the ogive of sensible heat flux provides an analytical approach to check for potential loss due to spectral attenuation or other factors (Oncely et al., 1996). When the data converge to 1 at low frequencies, this implies that all relevant eddies are well captured in one sampling period and no significant flux is transported by eddies beyond the duration of the sampling period. The ogives of all ions shown in the figure asymptotically approach 1 at low frequency, indicating that the sampling period of $27 \mathrm{~min}$ was sufficiently long. However, ogives of $w^{\prime}(m / z 61.027)^{\prime}, w^{\prime}(m / z 81.070)^{\prime}$, and $w^{\prime}(m / z \text { 93.069) })^{\prime}$ are shifted to lower frequency compared to those of $w^{\prime}(m / z 33.032)^{\prime}$ and $w^{\prime}(m / z 59.048)^{\prime}$ which are very similar to the $w^{\prime} T^{\prime}$ ogive. This indicates that there exist potential loss processes for these 3 compounds. In the case of acetic acid $(m / z$ 61.027) inlet dampening of high frequency variations may explain the shift; for the other compounds the reason for the shift towards lower frequencies is currently not well understood.

Overall, the spectral analysis presented here demonstrates that fluxes of BVOC are well measured by PTR-MS-TOFEC, except for some potential loss of flux for sticky compounds such as acetic acid. The analysis also demonstrates that BVOC fluxes at this site are likely controlled by different and sometimes even competing processes. In combination with canopy transport models the spectral information may prove useful for constraining the strength of individual sources/sinks such as biogenic emission, chemical production/loss, and dry deposition, and we recommend further research on this issue. 

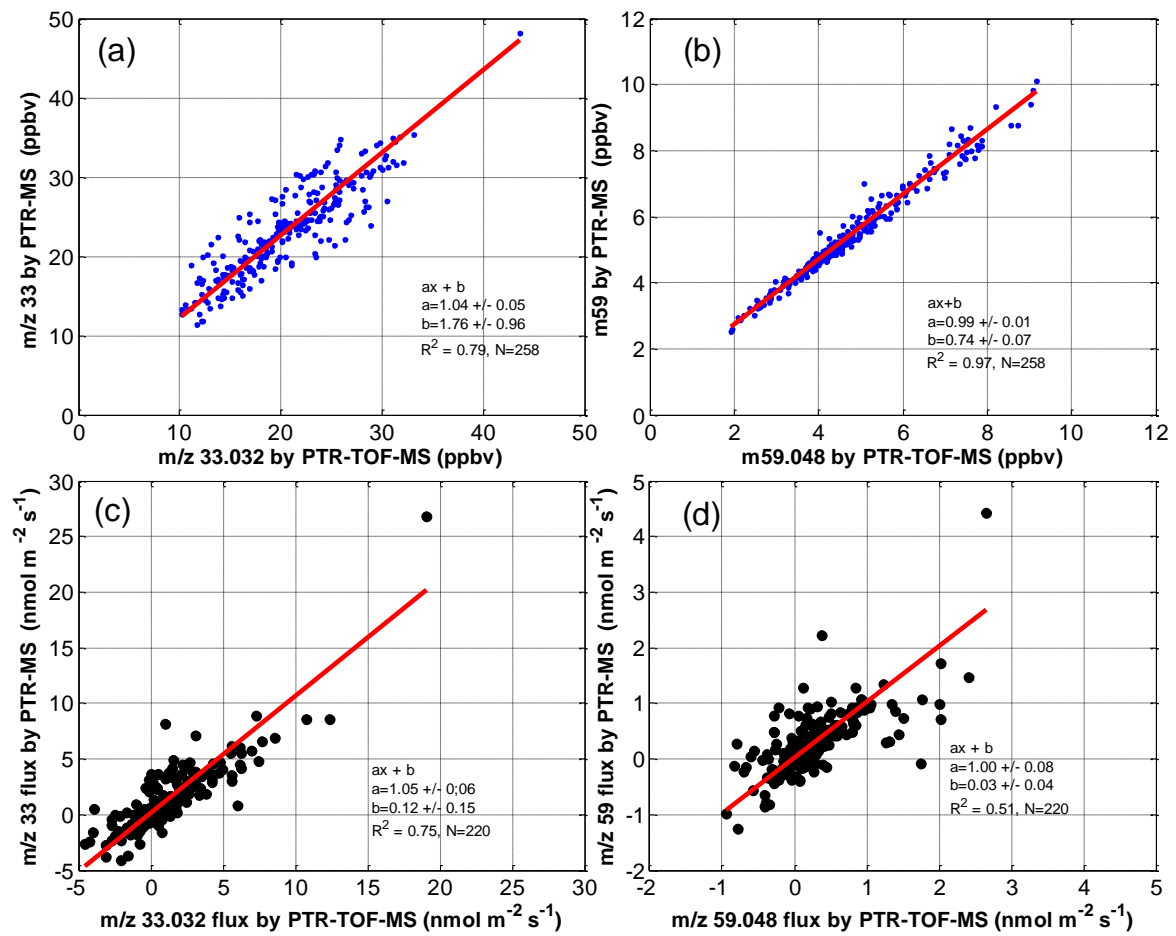

Fig. 6. PTR-MS and PTR-TOF-MS mixing ratio (a, b) and flux (c, d) inter-comparison for methanol (a, c) and acetone (b, d). Best fit is shown in red with fitting parameters given in the legends (slope, intercept and R-square).

\subsection{Intercomparison between PTR-TOF and PTR-MS}

\subsubsection{Mixing ratios and fluxes}

We compare measurements of methanol (monitored at $\mathrm{m} / \mathrm{z}$ 33.032 for PTR-TOF-MS and $m / z 33$ for PTR-MS) and acetone (monitored at $\mathrm{m} / z 59.048$ for PTR-TOF-MS and $\mathrm{m} / \mathrm{z}$ 59 for PTR-MS) to validate the performance of both PTRMS and PTR-TOF-MS for measuring ambient mixing ratios and fluxes. These two compounds exhibited high and variable mixing ratios and fluxes, were measured by both instruments through the same sampling inlet simultaneously, and were reliably calibrated using standard gases two times per day. For the other species commonly measured, $m / z 69$ and 113 showed relatively low mixing ratios and fluxes. Two distinct mass peaks on $\mathrm{m} / z, 113$ were identified by PTR-TOFMS measurement (Table 2). Monoterpene fluxes by PTR-MS were measured at only $m / z 81$ (a main fragment of monoterpenes), but we found that monoterpene fluxes were dominated by 3 different masses $(m / z$ 81.070, 95.086, 137.131). Fragmentation patterns of monoterpenes are highly dependent on $E / N$ ratio and the specific monoterpene mix. Therefore, we focus on comparison of methanol and acetone in this section.

Inter-comparison results (Fig. 6) are presented with linear fits based on the Williamson-York method reviewed by Cantrell (2008) considering uncertainties in both the $\mathrm{x}$ - and $y$-variables with all the same weights. Half-hour mean mixing ratios and fluxes are included from 14 July through 26 July when both instruments continuously operated without any critical maintenance issues. Mixing ratio measurements of methanol and acetone over the 12-day period generally agree well with slopes of $0.99\left(R^{2}=0.89\right)$ for methanol, and $0.99\left(R^{2}=0.97\right)$ for acetone. Methanol and acetone fluxes (Fig. 6c and d) also agree well between the two instruments with slopes of $1.05\left(R^{2}=0.75\right)$, and $1.00\left(R^{2}=0.51\right)$, respectively. However, the correlation coefficient for acetone is lower than for methanol owing to a few data points where PTR-TOF-MS measured higher fluxes than PTR-MS. This difference is likely attributed to loss of high frequency eddies in the PTR-MS measurement due to both the lower time resolution and the specificity of the disjunct data acquisition for each chemical compound. To investigate this further, we inspected the normalized co-spectra for acetone fluxes from both measurements checking which frequencies were carrying significant flux, and found that a large acetone upward flux at high frequency measured by PTR-TOF-MS might be not properly detected by PTR-MS, contributing to this discrepancy. Figure 7 shows an example for time 14:00 PST on 22 July 2010. Each line presents the normalized co-spectra of sensible heat flux (broken black line) and acetone flux; original $5 \mathrm{~Hz}$ data from PTR-TOF-MS (red line with open circle), $1 \mathrm{~Hz}$ reduced data from PTR-TOF-MS (solid cyan line), $1 \mathrm{~Hz}$ disjunct sub-sampled (similarly to PTR-MS data acquisition) 

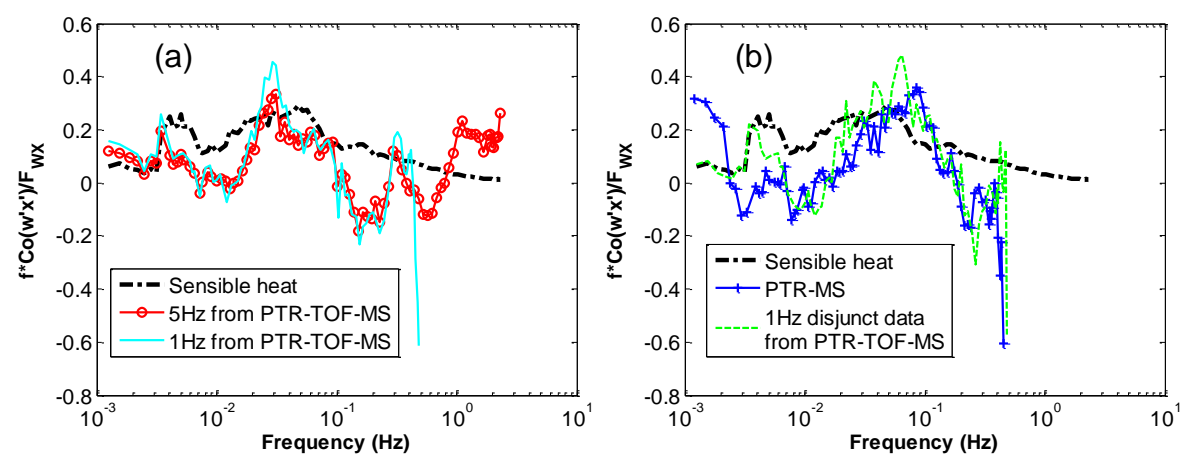

Fig. 7. Normalized co-spectra for vertical wind speed with sensible heat (broken black line) and acetone ( $\mathrm{m} / z$ 59.048 for PTR-TOF-MS and $m / z 59$ for PTR-MS) for 14:00 PST on 22 July, 2010, smoothed by averaging into 100 equally-spaced logarithmic bins. Each line presents the normalized co-spectra of sensible heat flux (broken black line) and acetone flux; (a) original $5 \mathrm{~Hz}$ data from PTR-TOF-MS (red line with open circle), $1 \mathrm{~Hz}$ reduced data from PTR-TOF-MS (solid cyan line), (b) $1 \mathrm{~Hz}$ disjunct sub-sampled (similarly to PTR-MS data acquisition) from PTR-TOF-MS (dotted green line), and $\sim 1 \mathrm{~Hz}$ disjunct data from PTR-MS (solid blue line with plus).

from PTR-TOF-MS (dotted green line), and $\sim 1 \mathrm{~Hz}$ disjunct data from PTR-MS (solid blue line with plus). This comparison demonstrates that a significant portion of acetone flux occurred at high frequencies $(>\sim 0.9 \mathrm{~Hz})$ during this $30 \mathrm{~min}$ period, and PTR-MS was not able to capture this feature due to lower time resolution. Of interest, disjunct data acquisition also affected the reliability of turbulent transport information. Figure $7 \mathrm{~b}$ shows co-spectra of $1 \mathrm{~Hz}$ disjunct data from both instruments, and maximum peaks are located at higher frequency (between $0.06-0.09 \mathrm{~Hz}$ ) than that of continuous data $(\sim 0.03 \mathrm{~Hz})$ shown in Fig. $7 \mathrm{a}$, in spite of good agreement between the co-spectra within each panel, indicating noncontinuous data may lose real flux information. From this example, $1 \mathrm{~Hz}$ continuous and disjunct data lost respectively $24 \%\left(1.34 \mathrm{nmol} \mathrm{m}^{-2} \mathrm{~s}^{-1}\right)$ and $39 \%\left(1.07 \mathrm{nmol} \mathrm{m}^{-2} \mathrm{~s}^{-1}\right)$ of flux estimated by $5 \mathrm{~Hz}$ continuous data $\left(1.76 \mathrm{nmol} \mathrm{m}^{-2}\right.$ $\mathrm{s}^{-1}$ ). This phenomenon occurred similarly for methanol, but the portion of high frequency flux was lower than for acetone and had much less effect on the 30 min average flux. In addition, slightly different time windows used for EC flux calculations from the 2 different instruments could contribute to this imperfect correlation. Overall, even though there are occasional discrepancies in flux between the two instruments, the differences were minor, and we conclude there were no significant instrumental biases in either mixing ratio or flux measurements.

\subsubsection{Fluxes by PTR-TOF-MS and vertical gradients by PTR-MS}

To check whether the observed vertical gradients were qualitatively in agreement with the observed direction of fluxes, we compare EC fluxes measured by PTR-TOF-MS and vertical gradients measured by PTR-MS. Lower (or higher) average mixing ratios with increasing height above the canopy normally indicate that there is emission (or deposition), re- spectively. PTR-TOF-MS EC flux data from the first 0-30 min and consecutive 6-min averaged PTR-MS data at 4 different heights from the second 30-60 min are used to represent each hour. Average diurnal profiles of fluxes and vertical gradients measured by PTR-TOF-MS and PTR-MS (respectively) are shown in Figs. 8-10 for the 6 species with the highest fluxes and/or mixing ratios which were measured by both instruments. In addition, we show the average diurnal flux of acetic acid detected by PTR-TOF-MS, because it was one of the species emitted in highest quantity, however its vertical gradients were not measured by PTR-MS.

Methanol is the most abundant non-methane VOC in the troposphere with mixing ratios often exceeding $10 \mathrm{ppbv}$ in the boundary layer in vegetated regions during summer (Goldan et al., 1995; Lamanna and Goldstein, 1999; Holzinger et al., 2001; Schade and Goldstein, 2006), and it is known to be either directly emitted from plants or deposited to wet surfaces such as leaves and soil (Schade et al., 2011; Karl et al., 2004). Consistently, methanol mixing ratios at this site were the highest of all the VOC observed with a range from 7.3-43.6 ppbv. Previous branch enclosure experiments for citrus species have demonstrated that methanol is the dominant VOC emitted on a molar basis (Fares et al., 2011). The diurnal cycle of vertical gradients (Fig. 8a) showed higher concentrations and stronger vertical gradients at nighttime than during daytime, while fluxes (Fig. 8c) were maximum during daytime around 15:00 PST, and small but measurable at night. The observed higher concentrations and larger vertical gradients at night are typical for species with temperature dependent emissions due to much faster vertical mixing during the day and stable atmospheric stratification during the night. Bi-directional fluxes for methanol, with emission in late evening and deposition in early morning, were clearly apparent in both the flux and vertical gradient directions, with the vertical gradients providing clear confirmation that the flux measurements of deposition were real. 

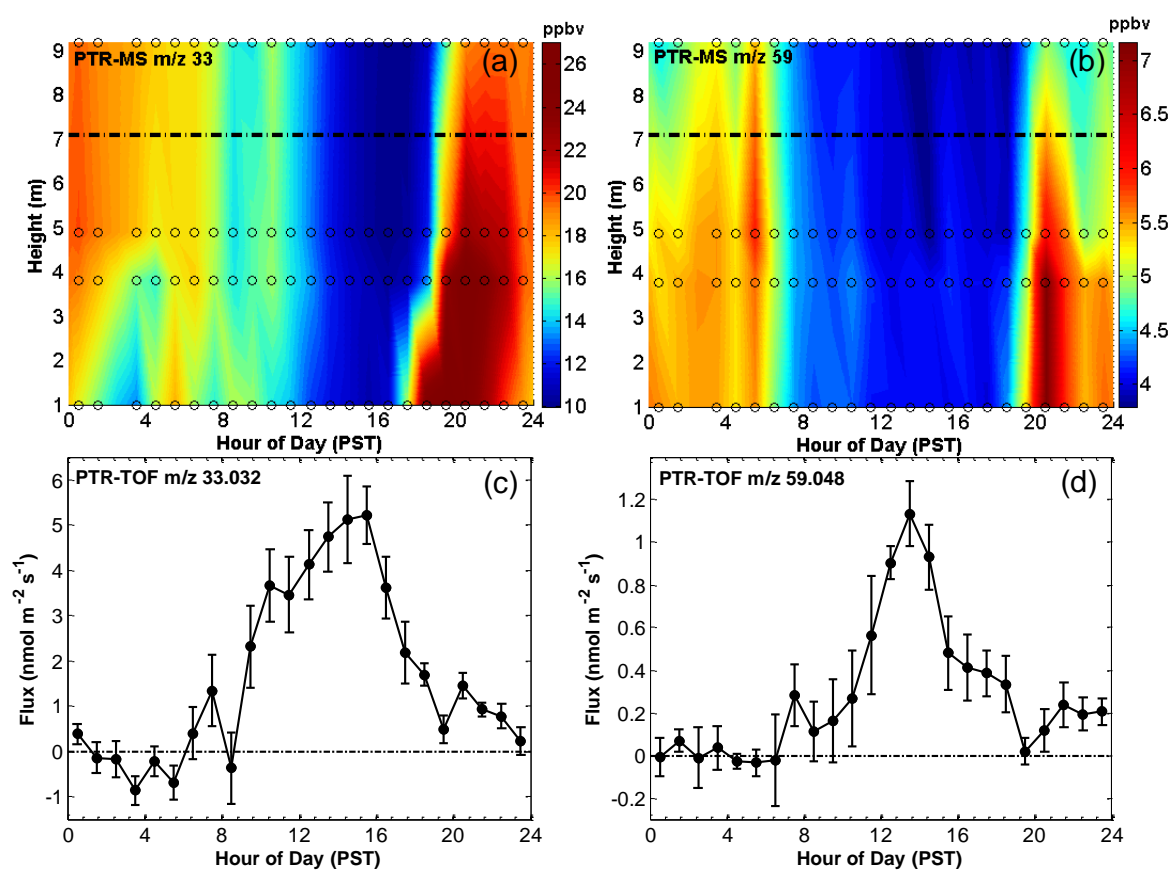

Fig. 8. Mean vertical gradient (a and b, PTR-MS) and flux (c and d, PTR-TOF-MS) diurnal patterns of methanol and acetone respectively. Interpolated gradient measurements (a and $\mathbf{b}$ ) are color coded with actual measurement timing and vertical positions shown as open circles, and flux measurement height shown as a broken black line. Flux diurnal patterns of methanol and acetone shown in (c) and (d) agree well with observed vertical gradients during day and night. Error bars in (c) and (d) denote the standard errors of all measurements at the respective hour of the day.

Acetone is ubiquitous in the troposphere, and it has a variety of sources including terrestrial vegetation, biomass burning, anthropogenic emissions, and photochemical production (Pöschl et al., 2001; Jacob et al., 2002; Schade and Goldstein, 2006). With a daytime average around $4 \mathrm{ppbv}$, our results were well within the range of previous studies. Vertical gradients of acetone (Fig. 8b) were very weak in the early morning (02:00-07:00 PST) and more clearly visible for the rest of the day. This pattern was consistent with the PTRTOF-MS EC measurements of high fluxes during the day, significant fluxes in the evening, and near zero fluxes in the early morning (Fig. 8d).

Acetaldehyde (Fig. 9a and d, monitored at $\mathrm{m} / z 45.033$ for PTR-TOF-MS and $m / z 45$ for PTR-MS) is emitted by live leaves, and has similar sources as acetone (Kesselmeier and Staudt, 1999; Schade and Goldstein, 2001). Ciccioli et al. (1999) observed comparable fluxes of acetone and acetaldehyde from an orange orchard in Spain. We measured a mean diurnal flux of up to $1.1 \mathrm{nmol} \mathrm{m}^{-2} \mathrm{~s}^{-1}$ for acetone and $0.7 \mathrm{nmol} \mathrm{m}^{-2} \mathrm{~s}^{-1}$ for acetaldehyde, so our results were in general agreement with Ciccioli et al. (1999). The directions of observed vertical gradient and EC flux of acetaldehyde were generally in agreement.

Methyl vinyl ketone and methacrolein (MVK+MACR; monitored at $m / z 71.048$ for PTR-TOF-MS and $m / z 71$ for PTR-MS) are well known as major secondary products from the atmospheric oxidation of isoprene. Recently, Karl et al. (2010) and Tani et al. (2010) have reported MVK+MACR can be taken up by plants during daytime, but Jardine et al. (2012) found these compounds can be directly emitted due to within plant isoprene oxidation. Our observations of both flux and vertical gradient in the orange grove indicate emission occurred through most of the day and night, with a short period of deposition in the early morning from 04:00-06:00 PST (Fig. 9b and e), and an overall net emission. Vertical gradients (Fig. 9b) suggested some deposition occurring between 02:00 and 04:00 PST, yet the mixing ratios at that time were highest at $5 \mathrm{~m}$, so the observed emission fluxes at $7.1 \mathrm{~m}$ were still consistent with the overall vertical gradient pattern. Our results for MVK+MACR clearly show bi-directional exchange but with a net emission from the orange orchard. This result contrasts with results of Karl et al. (2010) showing deposition dominating in multiple different ecosystems.

Toluene and a fragmentation product of para-cymene $\left(\mathrm{C}_{10} \mathrm{H}_{14} \mathrm{H}^{+}\right.$, monitored at $m / z 135.116$ in PTR-TOF) were detected at $m / z 93$ in PTR-MS and at $m / z 93.069$ in PTRTOF-MS. The fragment ion from para-cymene accounts for about $80 \%$ of total ions from para-cymene based on our $E / N$ ratios for both instruments (Tani et al., 2003; Ambrose et al., 2010). A few studies have claimed that toluene can be directly emitted from plants (Heiden et al., 1999; White et al., 2009), and also para-cymene emissions have been observed 

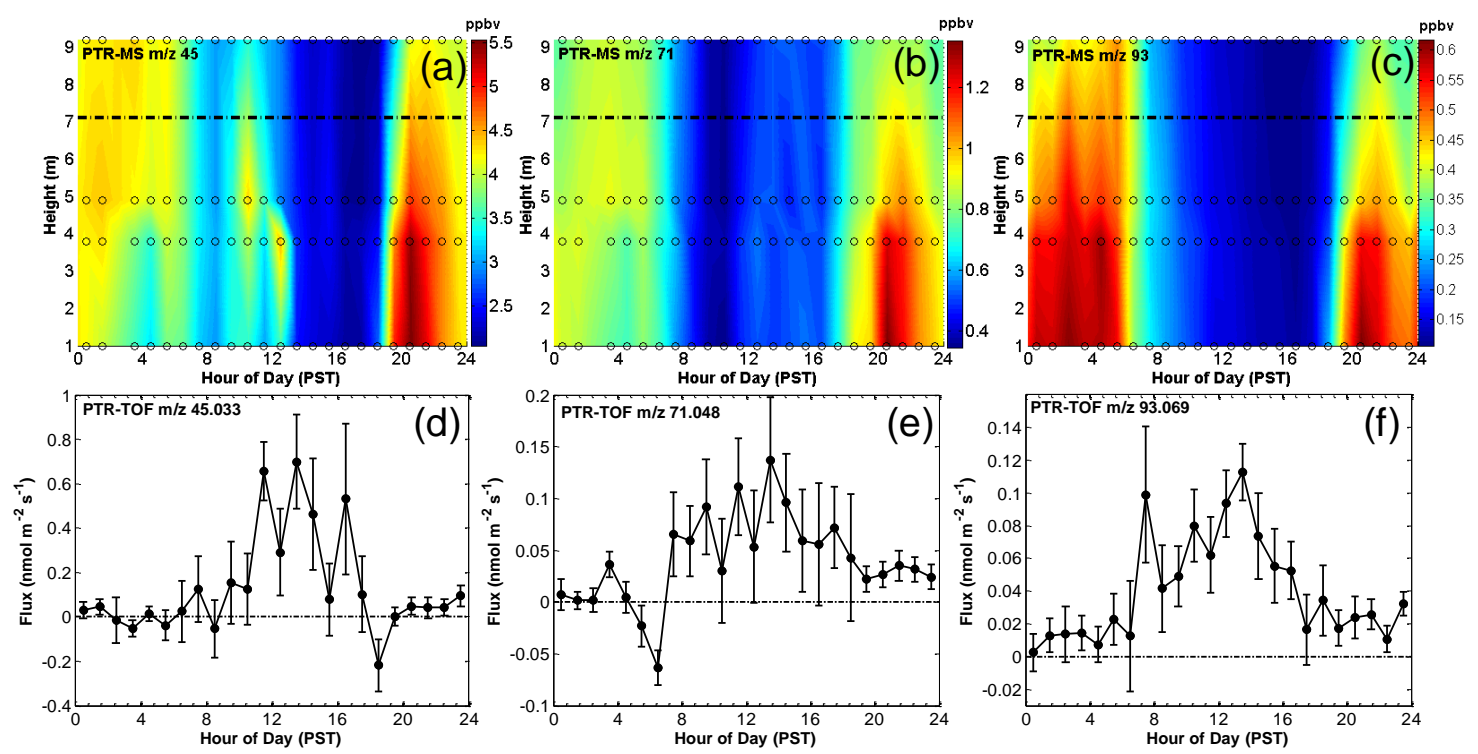

Fig. 9. Mean vertical gradient (a, b, and c, PTR-MS) and mean flux (d, e, and f, PTR-TOF-MS) diurnal patterns of acetaldehyde, MVK+MACR and para-cymene+toluene respectively. Symbols, color coding and error bars as in Fig. 8.

from orange trees (Ciccioli et al., 1999). Our observation of $m / z 93$ flux and vertical gradient showed upward flux throughout the day (Fig. 9c and f). In-situ gas chromatography (GC) measurements conducted during August 2010, (data do not overlap with this time period) recorded paracymene concentrations between $0.04 \mathrm{ppbv}$ and $0.84 \mathrm{ppbv}$, and toluene concentrations were half of that concentration or less, making the toluene concentrations often below the detection limit for PTR-MS and PTR-TOF-MS. Therefore, we infer para-cymene was probably the main contributor to fluxes and vertical gradients of $m / z 93$.

Monoterpenes are BVOC with chemical composition $\mathrm{C}_{10} \mathrm{H}_{16}$, and citrus trees emit various monoterpenes including limonene, ocimene, and sabinene (Fares et al., 2011; Ormeno et al., 2010; Ciccioli et al., 1999). PTR-MS or PTRTOF-MS systems monitor the sum of monoterpenes mainly at $m / z 137$ (or 137.131) $\left(\mathrm{C}_{10} \mathrm{H}_{16} \mathrm{H}^{+}\right.$), with a main fragment at $m / z 81$ (or 81.070) $\left(\mathrm{C}_{6} \mathrm{H}_{8} \mathrm{H}^{+}\right)$and several minor fragments including $m / z 95$ (or 95.086) $\left(\mathrm{C}_{7} \mathrm{H}_{10} \mathrm{H}^{+}\right)$. Fragments from sesquiterpenes (Kim et al., 2009) may also contribute to signals at the same masses, but their contribution should be minor because of very low concentrations. The fragmentation patterns are dependent on both the instrument operating conditions and the different monoterpene species present. Tani et al. (2003) reported fragmentation of d-limonene to $m / z 81,137$, and 95 with yields of $\sim 50 \%$, $\sim 30 \%$, and $\sim 10 \%$, respectively, based on our $E / N$ ratio condition $(\sim 150 \mathrm{Td})$. Misztal et al. (2012) showed the ratio of $m / z 81$ to $m / z 137$ for d-limonene increases at higher $E / N$ ratio (e.g., $\sim 6.5$ at $140 \mathrm{Td}$ ). Both Tani et al. (2003) and Misztal et al. (2012) showed different fragmentation patterns for several specific monoterpenes when changing the instrumental conditions. Our GC data at this site in August showed d-limonene contributed $89 \%$ to the sum of speciated monoterpene mixing ratios (Fares et al., 2012a). Therefore, $m / z 81.070$ fluxes measured by our PTR-TOF-MS should be higher than $m / z 137.131$ and $m / z$ 95.086, consistent with our results (Fig. 10b). All three of these masses showed emissions over the full day, consistent with vertical gradients observed by PTR-MS (Fig. 10a). Different ions of monoterpenes from the PTR-TOF-MS show different diurnal patterns which may indicate the existence of different emission mechanisms as sources for different monoterpenes.

In addition to the compounds measured by both instruments, acetic acid $\left(\mathrm{C}_{2} \mathrm{H}_{4} \mathrm{O}_{2} \mathrm{H}^{+}\right.$; detected at $\mathrm{m} / z 61.027$ in PTR-TOF-MS but not measured by PTR-MS) was among the top 5 emitted species with mixing ratios between $2-$ $12 \mathrm{ppbv}$ and a daytime flux about $1 \mathrm{nmol} \mathrm{m}^{-2} \mathrm{~s}^{-1}$ (Fig. 11). Acetic acid is known to be produced or consumed in plants by metabolism processes, the central respiratory/biosynthetic intermediate acetyl-CoA. A few branch enclosure and field experiments showed emission from trees and deposition to surfaces of plants or wet soil surfaces (Kesselmeier and Staudt, 1999; Kesselmeier, 2001; Jardine et al., 2011). However the biosphere-atmosphere exchange of acetic acid has not been extensively studied. Moreover, we did not have an authentic standard for acetic acid during the field campaign and more work is necessary to validate its concentration in PTR-TOF-MS measurements. Acetic acid is highly condensable and sticky, so some of it is likely lost to the walls of sampling tubes as discussed in Sect. 3.2. Nevertheless, our data showed clear acetic acid emission from this site, and but we think these measured fluxes might underestimate the actual flux. 


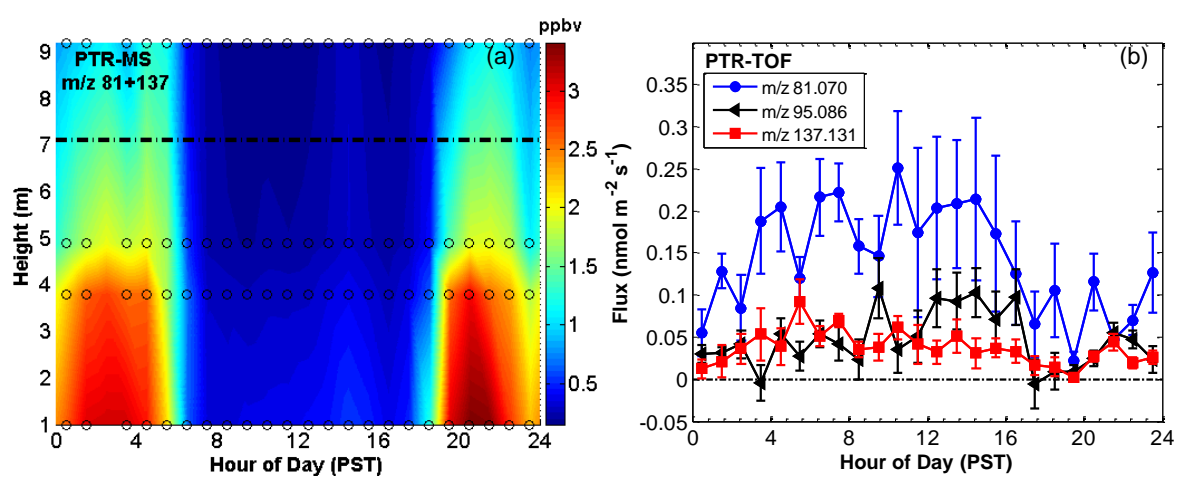

Fig. 10. (a) Total monoterpenes vertical gradient from PTR-MS as a sum of $m / z 81$ and 137, and (b) flux of individual $m / z$ of 81.070 (in blue circle), 95.086 (in black triangle) and 137.131 (in red square) from PTR-TOF-MS with standard errors (error bars). Gradient pattern and flux both show emission throughout the day and $\mathrm{m} / \mathrm{z} 81.070$ (main fragment of monoterpenes) shows the largest flux among the 3 ions.

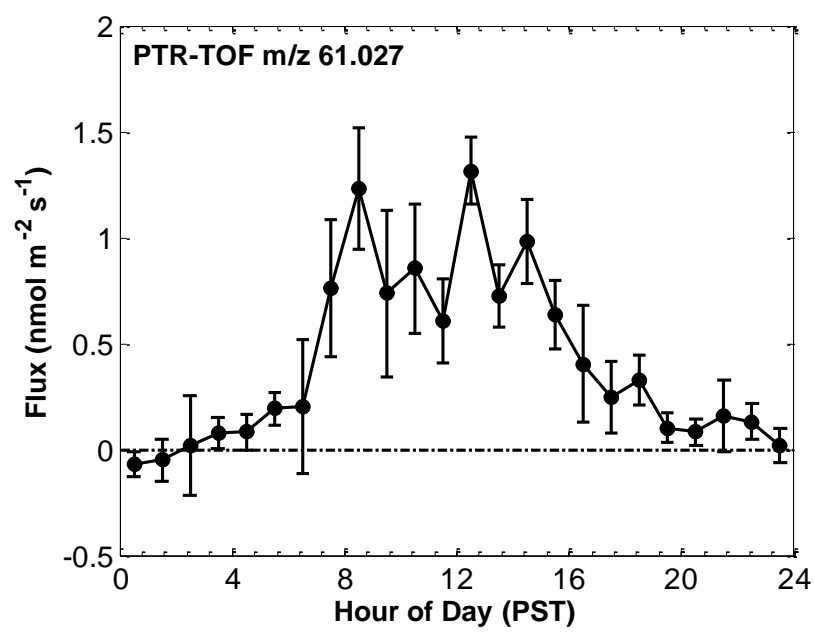

Fig. 11. Diurnal variation of $m / z 61.027$ (acetic acid) fluxes with standard errors.

For other OVOC (Table 2), we observed bi-directional fluxes with relatively small magnitudes (daytime average up to $0.016 \mathrm{nmol} \mathrm{m}^{-2} \mathrm{~s}^{-1}$ for emission and $-0.004 \mathrm{nmol} \mathrm{m}^{-2} \mathrm{~s}^{-1}$ for deposition) compared to the compounds described above. The emissions of these OVOC may be a result of oxidation processes within the canopy or direct emission from plants/soil. The observed depositions possibly suggest that parent hydrocarbon compounds either emitted from the site or advected from upwind sources are photochemically oxidized to form secondary compounds containing oxygen which are then removed from the atmosphere by dry deposition. In addition, we found at least 2 significant distinct mass peaks at each of the nominal $m / z .107,111,113$, and 139, indicating PTR-TOF-MS can efficiently separate among isobaric compounds and provide their empirical molecular formulae.

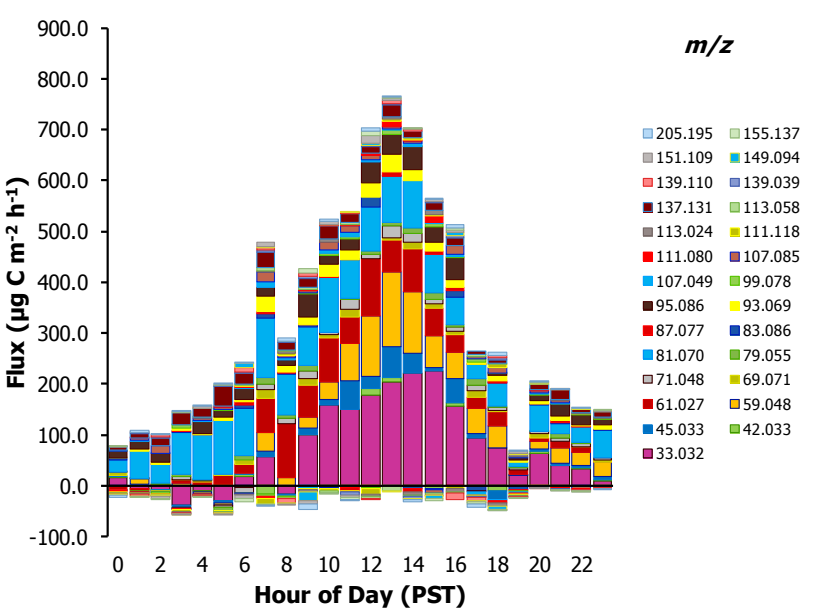

Fig. 12. Total and fractional BVOC diurnal flux measured by PTRTOF-MS on a carbon mass basis. Staged bar plots of 27 masses with the largest fluxes are shown throughout the day with $\mathrm{m} / \mathrm{z}$ indicated in the legend.

\subsection{Total BVOC fluxes}

Total BVOC fluxes are shown for the whole measurement period (Fig. 12). The fluxes shown include the 27 masses evaluated and are expressed in units $\mu \mathrm{g} \mathrm{m}^{-2} \mathrm{~h}^{-1}$. The carbon numbers were inferred from the ion species detected by PTR-TOF-MS, but 10 carbons were applied for $m / z 81.070$ and $m / z 95.086$ because these masses are known to mainly be due to fragmentation of monoterpenes $\left(\mathrm{C}_{10} \mathrm{H}_{16} \mathrm{H}^{+}\right)$.

Measured BVOC fluxes (Fig. 12) showed emissions at all times of day reaching a maximum of $765 \mu \mathrm{g} \mathrm{m}^{-2} \mathrm{~h}^{-1}$ (emissions of 25 masses) around hour 13:00-14:00 PST. During the night smaller but still positive fluxes were observed with a minimum of $79 \mu \mathrm{g} \mathrm{m}^{-2} \mathrm{~h}^{-1}$ (emissions of 15 masses) around hour 00:00-01:00 PST. About half of the species (12 ions) were observed to deposit 


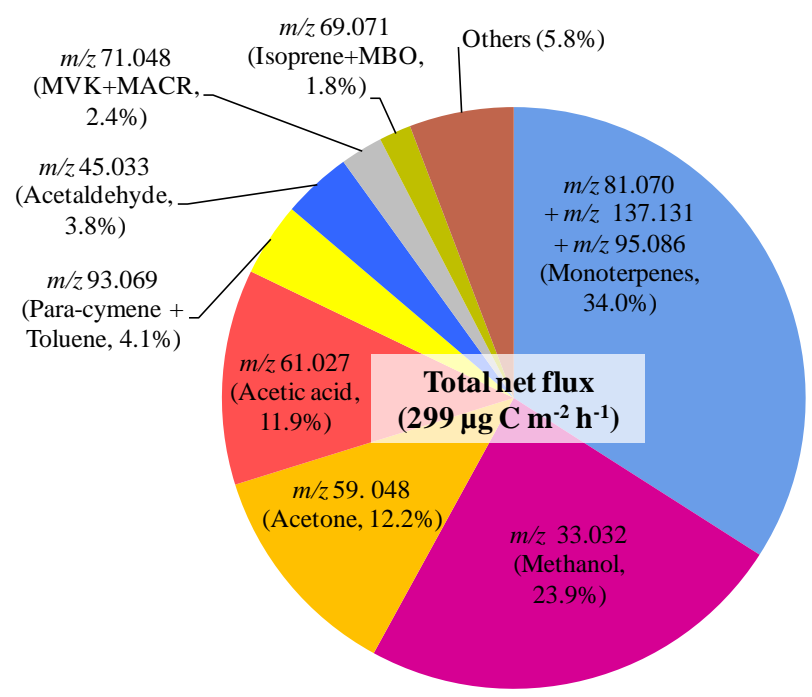

Fig. 13. Fractional contribution to the total flux for 27 ion species selected.

( $-57 \mu \mathrm{g} \mathrm{C} \mathrm{m}^{-2} \mathrm{~h}^{-1}$ ) during hour 03:00-04:00 PST. Sudden increases and decreases of fluxes at hour 07:00-08:00 and 19:00-20:00 PST were observed, respectively. This is likely due to transitions in boundary layer depth and atmospheric stability occurring at those times, so high concentrations at night are flushed out in the morning with high fluxes, and in the evening biogenic emissions start to accumulate in the in the surface layer canopy resulting in low fluxes. Bidirectional fluxes (either emission or deposition) for OVOC were observed, but we did not find any compounds which were uniformly deposited throughout the day.

By adding up all contributions to the total net flux over a day, a $24 \mathrm{~h}$ mean emission flux of $299 \mu \mathrm{g} \mathrm{C} \mathrm{m}{ }^{-2} \mathrm{~h}^{-1}$ was measured for the reported masses (Fig. 13). Terpene $(\mathrm{m} / \mathrm{z}$ 81.070, 95.086, and 137.131) emissions contributed $\sim 34 \%$ to total net carbon flux for selected masses, and this might be slightly underestimated since sesquiterpene $\left(\mathrm{C}_{15} \mathrm{H}_{24} \mathrm{H}^{+}\right)$ fragments, for which 15 carbons should be assumed, are also distributed on these $m / z$. However, fluxes measured for sesquiterpenes should be minor due to low concentration and fast photochemical destruction below our measurement height. Methanol $(\mathrm{m} / z$ 33.032) was the second largest emission at $24 \%$ of the total by mass, but represented the largest emission on a molar basis. Acetone $(m / z$ 59.048) and acetic acid $(m / z$ 61.027) fluxes were similar magnitude $(\sim 12 \%)$, followed by para-cymene + toluene $(m / z$ 93.069), acetaldehyde $(\mathrm{m} / \mathrm{z}$ 45.033), MVK+MACR $(\mathrm{m} / z$ 71.048), and isoprene+MBO $(\mathrm{m} / z$ 69.071) with $4.1,3.8,2.4$, and $1.8 \%$ contributions, respectively (Fig. 13). For the other 17 masses the net emission flux only contributed $5 \%$ to the total fluxes.

\section{Summary}

We successfully measured and evaluated eddy covariance emission and deposition fluxes for $27 \mathrm{~m} / z$ ratios using a high resolution PTR-TOF-MS instrument over an orange orchard in California's Central Valley. EC flux data by PTR-TOF-MS were validated through spectral analysis, were quantitatively inter-compared with PTR-MS measurement results for the mixing ratios and fluxes, and were qualitatively compared with vertical gradients from PTRMS for commonly measured compounds. Most of the observed compounds showed emissions from the surface. In addition, we found a significant emission of acetic acid which was only observed by PTR-TOF-MS measurement. Fluxes of terpenes, methanol, acetone, acetic acid, paracymene + toluene, and acetaldehyde contributed about $90 \%$ of the total flux of 27 masses observed by the PTRTOF-MS on a carbon mass basis. The dominant BVOC emissions from this site were monoterpenes $(\mathrm{m} / \mathrm{z} 81.070$ $\left.+m / z 137.131+m / z 95.086,34 \%, 102 \mu \mathrm{g} \mathrm{C} \mathrm{m}{ }^{-2} \mathrm{~h}^{-1}\right)$ and methanol $\left(\mathrm{m} / \mathrm{z} 33.032,23.9 \%, 72 \mu \mathrm{g} \mathrm{m}^{-2} \mathrm{~h}^{-1}\right)$ followed by acetone $\left(m / z 59.048,12.2 \%, 36.5 \mu \mathrm{g} \mathrm{C} \mathrm{m}^{-2} \mathrm{~h}^{-1}\right)$, acetic acid $\left(m / z 61.027,11.9 \%, 35.7 \mu \mathrm{g} \mathrm{C} \mathrm{m}^{-2} \mathrm{~h}^{-1}\right)$, para-cymene $\left(\mathrm{m} / \mathrm{z}\right.$ 93.069, $\left.4.1 \%, 12.2 \mu \mathrm{g} \mathrm{C} \mathrm{m}^{-2} \mathrm{~h}^{-1}\right)$, acetaldehyde $(\mathrm{m} / \mathrm{z}$ 45.033, $\left.3.8 \%, 11.5 \mu \mathrm{g} \mathrm{C} \mathrm{m}{ }^{-2} \mathrm{~h}^{-1}\right)$, MVK+MACR $(\mathrm{m} / \mathrm{z}$ 71.048, $\left.2.4 \%, 7.1 \mu \mathrm{g} \mathrm{C} \mathrm{m}{ }^{-2} \mathrm{~h}^{-1}\right)$, and isoprene+MBO $(\mathrm{m} / \mathrm{z}$ 69.071, $\left.1.8 \%, 5.3 \mu \mathrm{g} \mathrm{C} \mathrm{m}^{-2} \mathrm{~h}^{-1}\right)$. In addition, low levels ( $<1.6 \%$ for each, $5.8 \%$ in total flux) of emission/deposition for 17 masses were observed. We have demonstrated that EC flux measurement using PTR-TOF-MS provide a very powerful tool to investigate landscape scale exchanges of VOC and/or OVOC fluxes, observing both emissions and deposition simultaneously for a wide range of compounds.

Acknowledgements. This work has been supported by the Netherlands Organization for Scientific Research (NWO) under the ALW-Middelgroot program (Grant 834.08.002), the California Air Resources Board (Award 06-329), the Citrus Research Board, and the University of Utrecht short stay fellowship program. We thank the Gorden Ranch for hosting this study, and for the assistance provided by the UC Lindcove Research and Extension station.

Edited by: J. Thornton

\section{References}

Ambrose, J. L., Haase, K., Russo, R. S., Zhou, Y., White, M. L., Frinak, E. K., Jordan, C., Mayne, H. R., Talbot, R., and Sive, B. C.: A comparison of GC-FID and PTR-MS toluene measurements in ambient air under conditions of enhanced monoterpene loading, Atmos. Meas. Tech., 3, 959-980, doi:10.5194/amt-3959-2010, 2010.

Andreae, M. O. and Crutzen, P. J.: Atmospheric aerosols: Biogeochemical sources and role in atmospheric chemistry, Science, 276, 1052-1058, 1997. 
Baldocchi, D. D.: Assessing the eddy covariance technique for evaluating carbon dioxide exchange rates of ecosystems: past, present and future, Global Change Biol., 9, 479-492, 2003.

Baldocchi, D. D., Hicks, B. B., and Meyers, T. P.: Measuring Biosphere-Atmosphere Exchanges of Biologically Related Gases with Micrometeorological Methods, Ecology, 69, 13311340, 1988.

Bamberger, I., Hortnagl, L., Ruuskanen, T. M., Schnitzhofer, R., Muller, M., Graus, M., Karl, T., Wohlfahrt, G., and Hansel, A.: Deposition fluxes of terpenes over grassland, J. Geophys. Res.Atmos., 116, D14305, doi:10.1029/2010jd015457, 2011.

Bianco, L., Djalalova, I. V., King, C. W., and Wilczak, J. M.: Diurnal Evolution and Annual Variability of Boundary-Layer Height and Its Correlation to Other Meteorological Variables in California's Central Valley, Bound.-Lay. Meteorol., 140, 491-511, doi:10.1007/s10546-011-9622-4, 2011.

Bouvier-Brown, N. C., Goldstein, A. H., Gilman, J. B., Kuster, W. C., and de Gouw, J. A.: In-situ ambient quantification of monoterpenes, sesquiterpenes, and related oxygenated compounds during BEARPEX 2007: implications for gas- and particle-phase chemistry, Atmos. Chem. Phys., 9, 5505-5518, doi:10.5194/acp-9-5505-2009, 2009.

Businger, J. A. and Delany, A. C.: Chemical Sensor Resolution Required for Measuring Surface Fluxes by 3 Common Micrometeorological Techniques, J. Atmos. Chem., 10, 399-410, doi:10.1007/Bf00115782, 1990.

Cantrell, C. A.: Technical Note: Review of methods for linear leastsquares fitting of data and application to atmospheric chemistry problems, Atmos. Chem. Phys., 8, 5477-5487, doi:10.5194/acp8-5477-2008, 2008.

Chameides, W. L., Lindsay, R. W., Richardson, J., and Kiang, C. S.: The Role of Biogenic Hydrocarbons in Urban Photochemical Smog - Atlanta as a Case-Study, Science, 241, 1473-1475, 1988.

Ciccioli, P., Brancaleoni, E., Frattoni, M., Di Palo, V., Valentini, R., Tirone, G., Seufert, G., Bertin, N., Hansen, U., Csiky, O., Lenz, R., and Sharma, M.: Emission of reactive terpene compounds from orange orchards and their removal by within-canopy processes, J. Geophys. Res.-Atmos., 104, 8077-8094, 1999.

Dabberdt, W. F., Lenschow, D. H., Horst, T. W., Zimmerman, P. R., Oncley, S. P., and Delany, A. C.: Atmosphere-Surface Exchange Measurements, Science, 260, 1472-1481, 1993.

Davison, B., Taipale, R., Langford, B., Misztal, P., Fares, S., Matteucci, G., Loreto, F., Cape, J. N., Rinne, J., and Hewitt, C. N.: Concentrations and fluxes of biogenic volatile organic compounds above a Mediterranean macchia ecosystem in western Italy, Biogeosciences, 6, 1655-1670, doi:10.5194/bg-6-16552009, 2009.

de Gouw, J. and Warneke, C.: Measurements of volatile organic compounds in the earth's atmosphere using proton-transferreaction mass spectrometry, Mass Spectrom. Rev., 26, 223-257, doi:10.1002/Mas.20119, 2007.

DiGangi, J. P., Boyle, E. S., Karl, T., Harley, P., Turnipseed, A., Kim, S., Cantrell, C., Maudlin III, R. L., Zheng, W., Flocke, F., Hall, S. R., Ullmann, K., Nakashima, Y., Paul, J. B., Wolfe, G. M., Desai, A. R., Kajii, Y., Guenther, A., and Keutsch, F. N.: First direct measurements of formaldehyde flux via eddy covariance: implications for missing in-canopy formaldehyde sources, Atmos. Chem. Phys., 11, 10565-10578, doi:10.5194/acp-1110565-2011, 2011.
Fares, S., Gentner, D. R., Park, J. H., Ormeno, E., Karlik, J., and Goldstein, A. H.: Biogenic emissions from Citrus species in California, Atmos. Environ., 45, 4557-4568, doi:10.1016/j.atmosenv.2011.05.066, 2011.

Fares, S., Park, J.-H., Gentner, D. R., Weber, R., Ormeño, E., Karlik, J., and Goldstein, A. H.: Seasonal cycles of biogenic volatile organic compound fluxes and concentrations in a California citrus orchard, Atmos. Chem. Phys., 12, 9865-9880, doi:10.5194/acp12-9865-2012, 2012a.

Fares, S., Weber, R., Park, J.-H., Gentner, D., Karlik, J., and Goldstein, A. H.: Ozone deposition to an orange orchard: Partitioning between stomatal and non-stomatal sinks, Environ. Pollut., 169, 258-266, doi:10.1016/j.envpol.2012.01.030, 2012b.

Farmer, D. K., Wooldridge, P. J., and Cohen, R. C.: Application of thermal-dissociation laser induced fluorescence (TD-LIF) to measurement of $\mathrm{HNO}_{3}$, Salkyl nitrates, Speroxy nitrates, and $\mathrm{NO}_{2}$ fluxes using eddy covariance, Atmos. Chem. Phys., 6, 3471-3486, doi:10.5194/acp-6-3471-2006, 2006.

Foken, T. and Wichura, B.: Tools for quality assessment of surfacebased flux measurements, Agr. Forest Meteorol., 78, 83-105, 1996.

Fuentes, J. D., Lerdau, M., Atkinson, R., Baldocchi, D., Bottenheim, J. W., Ciccioli, P., Lamb, B., Geron, C., Gu, L., Guenther, A., Sharkey, T. D., and Stockwell, W.: Biogenic hydrocarbons in the atmospheric boundary layer: A review, B. Am. Meteorol. Soc., 81, 1537-1575, 2000.

Goldan, P. D., Kuster, W. C., Fehsenfeld, F. C., and Montzka, S. A.: Hydrocarbon measurements in the southeastern United States: The Rural Oxidants in the Southern Environment (ROSE) program 1990, J. Geophys. Res.-Atmos., 100, 25945-25963, 1995.

Goldstein, A. H. and Galbally, I. E.: Known and unexplored organic constituents in the earth's atmosphere, Environ. Sci. Technol., 41, 1514-1521, 2007.

Graus, M., Muller, M., and Hansel, A.: High Resolution PTRTOF: Quantification and Formula Confirmation of VOC in Real Time, J. Am. Soc. Mass Spectr., 21, 1037-1044, doi:10.1016/j.jasms.2010.02.006, 2010.

Guenther, A. B. and Hills, A. J.: Eddy covariance measurement of isoprene fluxes, J. Geophys. Res.-Atmos., 103, 13145-13152, 1998.

Guenther, A., Hewitt, C. N., Erickson, D., Fall, R., Geron, C., Graedel, T., Harley, P., Klinger, L., Lerdau, M., Mckay, W. A., Pierce, T., Scholes, B., Steinbrecher, R., Tallamraju, R., Taylor, J., and Zimmerman, P.: A Global-Model of Natural Volatile Organic-Compound Emissions, J. Geophys. Res.-Atmos., 100, 8873-8892, 1995.

Guenther, A., Karl, T., Harley, P., Wiedinmyer, C., Palmer, P. I., and Geron, C.: Estimates of global terrestrial isoprene emissions using MEGAN (Model of Emissions of Gases and Aerosols from Nature), Atmos. Chem. Phys., 6, 3181-3210, doi:10.5194/acp-63181-2006, 2006.

Hallquist, M., Wenger, J. C., Baltensperger, U., Rudich, Y., Simpson, D., Claeys, M., Dommen, J., Donahue, N. M., George, C., Goldstein, A. H., Hamilton, J. F., Herrmann, H., Hoffmann, T., Iinuma, Y., Jang, M., Jenkin, M. E., Jimenez, J. L., Kiendler-Scharr, A., Maenhaut, W., McFiggans, G., Mentel, Th. F., Monod, A., Prévôt, A. S. H., Seinfeld, J. H., Surratt, J. D., Szmigielski, R., and Wildt, J.: The formation, properties and impact of secondary organic aerosol: current and emerging issues, 
Atmos. Chem. Phys., 9, 5155-5236, doi:10.5194/acp-9-51552009, 2009.

Heiden, A. C., Kobel, K., Komenda, M., Koppmann, R., Shao, M., and Wildt, J.: Toluene emissions from plants, Geophys. Res. Lett., 26, 1283-1286, 1999.

Holzinger, R., Jordan, A., Hansel, A., and Lindinger, W.: Methanol measurements in the lower troposphere near Innsbruck (047 degrees $16^{\prime} \mathrm{N}$; 011 degrees 24' E), Austria, Atmos. Environ., 35, 2525-2532, 2001.

Holzinger, R., Kasper-Giebl, A., Staudinger, M., Schauer, G., and Röckmann, T.: Analysis of the chemical composition of organic aerosol at the Mt. Sonnblick observatory using a novel high mass resolution thermal-desorption proton-transfer-reaction mass-spectrometer (hr-TD-PTR-MS), Atmos. Chem. Phys., 10, 10111-10128, doi:10.5194/acp-10-10111-2010, 2010a.

Holzinger, R., Williams, J., Herrmann, F., Lelieveld, J., Donahue, N. M., and Röckmann, T.: Aerosol analysis using a ThermalDesorption Proton-Transfer-Reaction Mass Spectrometer (TDPTR-MS): a new approach to study processing of organic aerosols, Atmos. Chem. Phys., 10, 2257-2267, doi:10.5194/acp10-2257-2010, 2010b.

Horst, T. W.: A simple formula for attenuation of eddy fluxes measured with first-order-response scalar sensors, Bound.-Lay. Meteorol., 82, 219-233, 1997.

Jacob, D. J., Field, B. D., Jin, E. M., Bey, I., Li, Q. B., Logan, J. A., Yantosca, R. M., and Singh, H. B.: Atmospheric budget of acetone, J. Geophys. Res.-Atmos., 107, 4100, doi:10.1029/2001jd000694, 2002.

Jang, M. S., Czoschke, N. M., Lee, S., and Kamens, R. M.: Heterogeneous atmospheric aerosol production by acid-catalyzed particle-phase reactions, Science, 298, 814-817, 2002.

Jardine, K., Yañez Serrano, A., Arneth, A., Abrell, L., Jardine, A., Artaxo, P., Alves, E., Kesselmeier, J., Taylor, T., Saleska, S., and Huxman, T.: Ecosystem-scale compensation points of formic and acetic acid in the central Amazon, Biogeosciences, 8, 37093720, doi:10.5194/bg-8-3709-2011, 2011.

Jardine, K. J., Monson, R. K., Abrell, L., Saleska, S. R., Arneth, A., Jardine, A., Ishida, F. Y., Yañez Serrano, A. M., Artaxo, P., Karl, T., Fares, S., Goldstein, A., Loreto, F., and Huxman, T.: Within-plant isoprene oxidation confirmed by direct emissions of oxidation products methyl vinyl ketone and methacrolein, Glob. Change Biol., 18, 973-984, doi:10.1111/j.1365-2486.2011.02610.x, 2012.

Jordan, A., Haidacher, S., Hanel, G., Hartungen, E., Mark, L., Seehauser, H., Schottkowsky, R., Sulzer, P., and Mark, T. D.: A high resolution and high sensitivity proton-transfer-reaction time-offlight mass spectrometer (PTR-TOF-MS), Int. J. Mass Spectrom., 286, 122-128, doi:10.1016/j.ijms.2009.07.005, 2009.

Karl, T. G., Spirig, C., Rinne, J., Stroud, C., Prevost, P., Greenberg, J., Fall, R., and Guenther, A.: Virtual disjunct eddy covariance measurements of organic compound fluxes from a subalpine forest using proton transfer reaction mass spectrometry, Atmos. Chem. Phys., 2, 279-291, doi:10.5194/acp-2-279-2002, 2002.

Karl, T., Potosnak, M., Guenther, A., Clark, D., Walker, J., Herrick, J. D., and Geron, C.: Exchange processes of volatile organic compounds above a tropical rain forest: Implications for modeling tropospheric chemistry above dense vegetation, J. Geophys. Res.-Atmos., 109, D18306, doi:10.1029/2004jd004738, 2004.
Karl, T., Harley, P., Emmons, L., Thornton, B., Guenther, A., Basu, C., Turnipseed, A., and Jardine, K.: Efficient Atmospheric Cleansing of Oxidized Organic Trace Gases by Vegetation, Science, 330, 816-819, doi:10.1126/science.1192534, 2010.

Kesselmeier, J.: Exchange of short-chain oxygenated volatile organic compounds (VOCs) between plants and the atmosphere: A compilation of field and laboratory studies, J. Atmos. Chem., 39, 219-233, 2001.

Kesselmeier, J. and Staudt, M.: Biogenic volatile organic compounds (VOC): An overview on emission, physiology and ecology, J. Atmos. Chem., 33, 23-88, 1999.

Kim, S., Karl, T., Helmig, D., Daly, R., Rasmussen, R., and Guenther, A.: Measurement of atmospheric sesquiterpenes by proton transfer reaction-mass spectrometry (PTR-MS), Atmos. Meas. Tech., 2, 99-112, doi:10.5194/amt-2-99-2009, 2009.

Lamanna, M. S. and Goldstein, A. H.: In situ measurements of C2-C-10 volatile organic compounds above a Sierra Nevada ponderosa pine plantation, J. Geophys. Res.-Atmos., 104, $21247-$ 21262, 1999.

Lee, X., Massman, W. J., and Law, B. E.: Handbook of micrometeorology : a guide for surface flux measurement and analysis, Atmospheric and oceanographic sciences library, 29, Kluwer Academic, Dordrecht; Boston; London, xiv, 250 pp., 2004.

Lenschow, D. H. and Kristensen, L.: Uncorrelated noise in turbulence measurements, J. Atmos. Ocean. Technol., 2, 68-81, 1985.

Lindinger, W., Hansel, A., and Jordan, A.: On-line monitoring of volatile organic compounds at pptv levels by means of protontransfer-reaction mass spectrometry (PTR-MS) - Medical applications, food control and environmental research, Int. J. Mass Spectrom., 173, 191-241, 1998.

Massman, W. J.: The Attenuation of Concentration Fluctuations in Turbulent-Flow through a Tube, J. Geophys. Res.-Atmos., 96, 15269-15273, 1991.

Misztal, P. K., Heal, M. R., Nemitz, E., and Cape, J. N.: Development of PTR-MS selectivity for structural isomers: Monoterpenes as a case study, Int. J. Mass Spectrom., 310, 10-19, 2012.

Moore, C. J.: Frequency-Response Corrections for EddyCorrelation Systems, Bound.-Lay. Meteorol., 37, 17-35, 1986.

Müller, M., Graus, M., Ruuskanen, T. M., Schnitzhofer, R., Bamberger, I., Kaser, L., Titzmann, T., Hörtnagl, L., Wohlfahrt, G., Karl, T., and Hansel, A.: First eddy covariance flux measurements by PTR-TOF, Atmos. Meas. Tech., 3, 387-395, doi:10.5194/amt-3-387-2010, 2010.

Oncley, S. P., Friehe, C. A., Larue, J. C., Businger, J. A., Itsweire, E. C., and Chang, S. S.: Surface-layer fluxes, profiles, and turbulence measurements over uniform terrain under near-neutral conditions, J. Atmos. Sci., 53, 1029-1044, 1996.

Ormeño, E., Gentner, D. R., Fares, S., Karlik, J., Park, J. H., and Goldstein, A. H.: Sesquiterpenoid Emissions from Agricultural Crops: Correlations to Monoterpenoid Emissions and Leaf Terpene Content, Environ. Sci. Technol., 44, 3758-3764, doi:10.1021/Es903674m, 2010.

Pierce, T., Geron, C., Bender, L., Dennis, R., Tonnesen, G., and Guenther, A.: Influence of increased isoprene emissions on regional ozone modeling, J. Geophys. Res.-Atmos., 103, 2561125629, 1998.

Pöschl, U., Williams, J., Hoor, P., Fischer, H., Crutzen, P. J., Warneke, C., Holzinger, R., Hansel, A., Jordan, A., Lindinger, 
W., Scheeren, H. A., Peters, W., and Lelieveld, J.: High acetone concentrations throughout the $0-12 \mathrm{~km}$ altitude range over the tropical rainforest in Surinam, J. Atmos. Chem., 38, 115-132, 2001.

Ritter, J. A., Lenschow, D. H., Barrick, J. D. W., Gregory, G. L., Sachse, G. W., Hill, G. F., and Woerner, M. A.: Airborne Flux Measurements and Budget Estimates of Trace Species over the Amazon Basin during the Gte Able-2b Expedition, J. Geophys. Res.-Atmos., 95, 16875-16886, 1990.

Ruuskanen, T. M., Müller, M., Schnitzhofer, R., Karl, T., Graus, M., Bamberger, I., Hörtnagl, L., Brilli, F., Wohlfahrt, G., and Hansel, A.: Eddy covariance VOC emission and deposition fluxes above grassland using PTR-TOF, Atmos. Chem. Phys., 11, 611-625, doi:10.5194/acp-11-611-2011, 2011.

Schade, G. W. and Goldstein, A. H.: Fluxes of oxygenated volatile organic compounds from a ponderosa pine plantation, J. Geophys. Res.-Atmos., 106, 3111-3123, 2001.

Schade, G. W. and Goldstein, A. H.: Seasonal measurements of acetone and methanol: Abundances and implications for atmospheric budgets, Global Biogeochem. Cy., 20, Gb1011, doi:10.1029/2005gb002566, 2006.

Schade, G. W., Solomon, S. J., Dellwik, E., Pilegaard, K., and Ladstatter-Weissenmayer, A.: Methanol and other VOC fluxes from a Danish beech forest during late springtime, Biogeochemistry, 106, 337-355, doi:10.1007/s10533-010-9515-5, 2011.
Shaw, W. J., Spicer, C. W., and Kenny, D. V.: Eddy correlation fluxes of trace gases using a tandem mass spectrometer, Atmos. Environ., 32, 2887-2898, 1998.

Tani, A., Hayward, S., and Hewitta, C. N.: Measurement of monoterpenes and related compounds by proton transfer reaction-mass spectrometry (PTR-MS), Int. J. Mass Spectrom., 223, 561-578, 2003.

Tani, A., Tobe, S., and Shimizu, S.: Uptake of Methacrolein and Methyl Vinyl Ketone by Tree Saplings and Implications for Forest Atmosphere, Environ. Sci. Technol., 44, 7096-7101, doi:10.1021/Es1017569, 2010.

White, M. L., Russo, R. S., Zhou, Y., Ambrose, J. L., Haase, K., Frinak, E. K., Varner, R. K., Wingenter, O. W., Mao, H., Talbot, R., and Sive, B. C.: Are biogenic emissions a significant source of summertime atmospheric toluene in the rural Northeastern United States?, Atmos. Chem. Phys., 9, 81-92, doi:10.5194/acp9-81-2009, 2009.

Wilczak, J. M., Oncley, S. P., and Stage, S. A.: Sonic anemometer tilt correction algorithms, Bound.-Lay. Meteorol., 99, 127-150, 2001.

Wolfe, G. M., Thornton, J. A., Yatavelli, R. L. N., McKay, M., Goldstein, A. H., LaFranchi, B., Min, K.-E., and Cohen, R. C.: Eddy covariance fluxes of acyl peroxy nitrates (PAN, PPN and MPAN) above a Ponderosa pine forest, Atmos. Chem. Phys., 9, 615-634, doi:10.5194/acp-9-615-2009, 2009. 